\title{
The Need for Restructuring the Disordered Science of Amorphous Drug Formulations
}

\author{
Khadijah Edueng ${ }^{1,2} \cdot$ Denny Mahlin ' • Christel A. S. Bergström '
}

Received: 25 February 2017 / Accepted: 1 May 2017 / Published online: 18 May 2017

(C) The Author(s) 2017. This article is an open access publication

\begin{abstract}
The alarming numbers of poorly soluble discovery compounds have centered the efforts towards finding strategies to improve the solubility. One of the attractive approaches to enhance solubility is via amorphization despite the stability issue associated with it. Although the number of amorphous-based research reports has increased tremendously after year 2000, little is known on the current research practice in designing amorphous formulation and how it has changed after the concept of solid dispersion was first introduced decades ago. In this review we try to answer the following questions: What model compounds and excipients have been used in amorphous-based research? How were these two components selected and prepared? What methods have been used to assess the performance of amorphous formulation? What methodology have evolved and/or been standardized since amorphous-based formulation was first introduced and to what extent have we embraced on new methods? Is the extent of research mirrored in the number of marketed amorphous drug products? We have summarized the history and evolution of amorphous formulation and discuss the current status of amorphous formulation-related research practice. We also explore the potential uses of old experimental methods and how they can be used in tandem with computational tools in designing amorphous formulation more efficiently than the traditional trial-and-error approach.
\end{abstract}

KEY WORDS amorphous solid dispersion · computational tools $\cdot$ crystallization $\cdot$ dissolution $\cdot$ stability

Christel A. S. Bergström

christel.bergstrom@farmaci.uu.se

Department of Pharmacy

Uppsala University, Uppsala Biomedical Centre

P.O. Box 580, SE-75I 23 Uppsala, Sweden

2 Kulliyyah of Pharmacy, International Islamic University Malaysia Jalan Istana, 25200 Bandar Indera Mahkota, Pahang, Malaysia

\author{
ABBREVIATIONS \\ API Active pharmaceutical ingredient \\ ASD Amorphous solid dispersion \\ BCS Biopharmaceutics classification system \\ BDM Biorelevent dissolution medium \\ DPD Dissipative particle dynamics \\ DSC Differential scanning calorimetry \\ GFA Glass forming ability \\ HBA Number of hydrogen bond acceptors \\ HBD Number of hydrogen bond donors \\ $H B N_{\text {eff }}$ Effective hydrogen bond number \\ $\mathrm{HCl} \quad$ Hydrochloric acid \\ logP Octanol-water partition coefficient \\ MD Molecular dynamics \\ MW Molecular weight \\ NMR Nuclear magnetic resonance \\ PSA Polar surface area \\ PVP Polyvinylpyrrolidone \\ R\&D Research and development \\ Ro5 Lipinski's rule-of-five \\ RotB Number of rotatable bonds \\ $\mathrm{T}_{\mathrm{g}} \quad$ Glass transition temperature \\ $\mathrm{T}_{\mathrm{m}} \quad$ Melting point \\ TTT Time-temperature-transformation \\ USP United States pharmacopoeia
}

\section{BACKGROUND}

Looking back in the scientific literature gives an interesting historic view on the use of amorphous solid dispersion (ASD) as a means of improving the dissolution of poorly soluble drugs. A number of publications from the 1960s reported the use of co-precipitates as formulation for poorly soluble drugs. Predominantly, these systems included a drug and a soluble component in an intimate mixture formed by coprecipitation from a common solvent via solvent evaporation. 
The water-soluble component was typically a polymer, for example polyvinylpyrrolidone (PVP) (1-3), or a low molecular weight compound such as urea (4).

In the 1960s, the primary aim of solid dispersions was to achieve improved dissolution for a poorly soluble drug. As it became apparent that ASD often results in supersaturation upon dissolution, the aim nowadays is predominantly to attain supersaturation. In 1960, Mullins and Macek (5) published a pioneer study of the dissolution behavior of a neat amorphous compound, novobiocin. In the study, the amorphous form and a salt of the drug were used and compared with the crystalline form. The study included evaluation of bioavailability. The authors screened 23 potential nucleation inhibitors which were added to reduce precipitation by crystallization of the drug from the supersaturated solutions formed during dissolution of the amorphous novobiocin. A few of these were identified as reducing precipitation during dissolution, one of these being PVP which is still used for the same purpose. Another early publication worth mentioning is that by Simonelli et al. (1), in which a theoretical model for dissolution of a solid dispersion of sulphathiazole and PVP was proposed.

The concept of a "solid dispersion" quickly evolved after 1961, when Sekiguchi and Obi (6) showed how to produce dispersion of a poorly soluble drug in a water-soluble carrier by forming an eutectic mixture for the purpose of improving oral absorption. Goldberg et al. (4) reviewed a number of reports on improving dissolution by forming eutectic mixtures but, importantly, the superior effects of a 'solid solution' were emphasized. The article also provided a theoretical description of the behavior of the crystalline phase in these solid mixtures. Solid dispersions and solid solutions that included an amorphous phase were reviewed later by Chiou and Riegelman (7). It was two years earlier (in 1969) (8) that the authors had introduced the term "glass solution" as a potential drug formulation concept in a study on the co-melting and solidification behavior of griseofulvin with citric acid. However, the term "glass solution" was replaced by the broader term "solid dispersion" and was then absent from the pharmaceutical literature until it was revived by Forster, Hempenstall and Rades in a series of publications in the early 2000s (9-11). It is interesting to note that, since 2009, the same type of system (drug and water-soluble, low-molecular-weight compound in an amorphous state) has often been referred to as "co-amorphous" (12-14). This type of formulation has attracted a great deal of interest for use with poorly soluble compounds.

In 1987, Doherty and York used the term ASD to describe the amorphous mixture of furosemide and PVP (15). The interactions between the components were studied using infrared spectroscopy and nuclear magnetic resonance (NMR) techniques, and the idea of strong interactions between the two components being important for amorphous formulation performance was introduced (15). In the same year, El-Hinnawi and Hajib used the same techniques for studying amorphous ibuprofen-PVP (16). Both these publications indicated that the systems studied were actually "glass solutions", but in the publications, the authors used the general term "solid dispersion". After the publication of the highly cited article by Taylor and Zografi on the interactions between indomethacin and PVP in 1997 (17) ASD became a recognized terminology and is widely used thereafter in pharmaceutical research for this type of amorphous mixture.

In the 1990s, a number of publications by Zografi and coworkers showed how the glass transition temperature $\left(T_{g}\right)$ is dependent on the composition of the amorphous mixture $(18,19)$ and the role of water sorption was also evaluated (20,21). This was the starting point for numerous investigations into the role of $\mathrm{T}_{\mathrm{g}}$ and molecular mobility in the physical stability of amorphous systems, and their relationship with the interactions between polymeric stabilizers and the amorphous component. In 1995, Hancock et al. (22) proposed a relationship between $\mathrm{T}_{\mathrm{g}}$ and the storage stability, stating that if an amorphous system was stored $50^{\circ} \mathrm{C}$ below its $\mathrm{T}_{\mathrm{g}}$, the shelf life would be prolonged for years. By the turn of the century, a range of research groups were interested in molecular mobility, as exemplified by the number of reports of different techniques for measuring mobility, such as dielectric spectroscopy (19,23-25), relaxation by differential scanning calorimetry (DSC) $(22,26)$ and NMR (27).

It is interesting to observe in the research reports from the 1990s that the polymeric additive used to reduce molecular mobility in amorphous drugs was often seen as a stabilizing additive for the amorphous phase, rather than as a watersoluble matrix as in the solid dispersions in the previous works. The notation "solid dispersion" remained, however, and this terminology now includes most types of amorphous drug/ polymer combinations.

Although the solubility advantage of amorphous compounds has been of great interest for a long time, the problem of unstable supersaturation causing difficulties with measuring the amorphous solubility has impeded efforts to better understand these systems. This was emphasized by Hancock and Parks in 2000 (28), who reported only five published amorphous solubility studies, including the one on novobiocin from 1960. After 2000, the number of publications on ASDs has increased tremendously. In this review the most recent of these have been studied to analyze the general understanding of these systems. In focus of the analysis are the drug properties, excipient selection, choice of production method and exploration of performance during dissolution, to provide an updated view on the gaps currently present in this research field. 


\section{CURRENT STATUS OF RESEARCH ON AMORPHOUS FORMULATIONS}

A literature review was carried out to provide an updated view of compounds, excipients and methods currently being explored for the production of stable amorphous drug formulations. One hundred-one articles relevant to the topic of interest published between January 2011 and December 2016 were found using the PubMed database and the search string "amorphous AND solid AND dispersions AND poorly AND soluble AND drug AND polymers OR polymer". The results were sub-classified into four important aspects of amorphous formulation and assessment: (i) which compounds were being investigated during this time frame?; (ii) how were excipients selected?; (iii) what was the processing technology or method of preparation?; and (iv) how was the performance of the amorphous formulation assessed (physical stability, apparent solubility and dissolution profiles)?

\section{Selection of Model Compound}

The current trend for newly discovered compounds to be poorly soluble (70-90\% of all new compounds are poorly soluble (29)) has been attributed to the chemical processes used for synthesis (30), the organizational behavior of large research organizations $(31,32)$, and the target biology (33-35). The molecular features that result in limited solubility and/or a reduced dissolution rate have been defined. Typically these features are used to divide drug molecules into two major categories: molecules showing solid-state-limited solubility (also colloquially called 'brick-dust' molecules to show that they form strong, tightly associated intermolecular bonds in a dense crystal lattice) and molecules showing solvation-limited solubility (also colloquially called 'greaseball' molecules to show that they have poor interactions with water molecules and tend to aggregate when exposed to water). Compounds with high $\left(>200^{\circ} \mathrm{C}\right)$ melting points $\left(\mathrm{T}_{\mathrm{m}}\right)$ and moderate lipophilicity (a partition coefficient between octanol and water, $\log \mathrm{P}$, of $<2$ ) are classified as 'brick-dust' molecules, whereas those with high lipophilicity $(\log \mathrm{P}>3)$, higher molecular weight ( $\sim \mathrm{MW}>400 \mathrm{~g} / \mathrm{mol})$, and a poorly integrated electron system are typically identified as 'grease-ball' molecules $(36,37)$. Some compounds have both a high $\mathrm{T}_{\mathrm{m}}$ and a high $\log \mathrm{P}$ which indicate limited solubility from both the solid state and solvation aspects.

Amorphization is an attractive approach to increase both the solubility (where the solubility of the amorphous form rather than the crystalline form is the important factor) and the dissolution rate (38-43). This approach should be possible for both categories of drug discussed above, but brick-dust compounds will probably benefit more from amorphization. This is because, in order to increase the apparent solubility and the dissolution rate of the solid state-limited compounds, the strong crystal lattice has to be weakened. This can be achieved by using another polymorph (44), by introduction of co-formers to produce co-crystals $(45,46)$, by selecting a salt of the drug (47), by making use of prodrug strategies (48), nanocrystal technologies $(49,50)$ or by using amorphization (or formation of amorphous nanoparticles) (51-53). For a long period, amorphization was not the first choice because of the inherent instability issues resulting from the high energy form of the amorphous solid material (as indicated in the Background section). However, since poor solubility is now a hurdle for so many newly discovered compounds, all means possible are currently investigated in order to improve the compound properties (54). It appears that the scientists formulating new compounds have embraced the amorphous solid dosage forms to a greater extent during the last five years than was apparent during the early 2000s. This was to some extent confirmed by a search of the PubMed database using the search string described above. Twenty-seven articles on amorphous solid dispersions were published between January 2000 and December 2010 (eleven years), which is only $27 \%$ of the number reported for the last six years (the period covered in this review).

In an amorphous solid, the strong intermolecular bonds within the crystal lattice are lost and there is no long-range order; this more random order in the interactions between the drug molecules results in an increase in the free energy of the amorphous system. However, improvement in the overall dissolution profile of the amorphized compound is not only dependent on disruption of the crystal lattice. When producing, for example, an ASD, the solubility and dissolution are also often improved by the reduction in particle size and the increased hydrophilicity (and resultant improved wettability) caused by the addition of hydrophilic and/or amphiphilic excipients (51). Thus, the formation of ASDs can be beneficial for both brick-dust and grease-ball drug molecules.

Compounds which demonstrate good glass-forming ability (GFA) and have a low crystallization tendency (good physical stability) are potential candidates for formulation as ASD (55-59). In 2010, Baird et al. classified 51 organic compounds into three groups based on their GFAs and crystallization tendencies (56). The compounds were classified as glass formers (classes II and III) or non-glass formers (class I), according to their crystallization behavior during the heating/cooling/ heating cycle, as measured by differential scanning calorimetry (56). Class I compounds were defined as those that crystallized during the period as the melt cooled, thus not existing in an amorphous form at, for example, room temperature. Class III compounds were defined as those forming a stable glass on melting that did not recrystallize during either cooling or the second heating. Class II compounds were defined as nonstable glass formers that recrystallized during the second heating. A similar but larger study was performed by Alhalaweh et al. in 2014. They used computational modeling 
to relate the physicochemical properties of 131 compounds to their GFAs and crystallization tendencies (60). In a different but related study, Wyttenbach et al. studied 54 compounds to ascertain the extent to which the Prigogine-Defay ratio could be used to predict the GFA (61). The physical stability (dry state) of amorphized compounds has also been explored (61) and Nurzyn'ska et al. recently presented data on the parameters related to the long-term stability of amorphous drugs (62). The findings from recent studies on GFA and crystallization behavior can be summarized thus:

- Characteristics indicating glass-forming compounds include: $\mathrm{MW}>300 \mathrm{~g} / \mathrm{mol}$, torsional bonds $(\tau)>4$, and effective hydrogen bond number $\left(\mathrm{HBN}_{\mathrm{eff}}\right)<6 \times 10^{-3}$ (60,61,63).

- Molecules with more branching, less symmetry, and a low number of benzene rings are good glass formers (64).

- Compounds with a high crystallization temperature $\left(>100^{\circ} \mathrm{C}\right)$, a high Hückel pi atomic charge for carbon atoms, and the capacity to form hydrogen bonds appear to be Class III glass formers (60).

- A high crystallization temperature $\left(>100^{\circ} \mathrm{C}\right)$, a high Hückel pi atomic charge for carbon atoms, and a high aromaticity are associated with physically stable glass at room temperature $(63,65)$.

Improved understanding of the physicochemical properties influencing the GFA and crystallization tendency of amorphous compounds is required to establish a science-based decision gateway on when to use an amorphous formulation to improve the solubility of poorly soluble compounds.

Consequently, we reviewed the recent literatures for commonly studied compounds formulated as amorphous systems to extract information about the physicochemical space currently being explored for this formulation area (Fig. 1). In particular, we investigated the relationships between amorphization and molecular size and complexity (MW, number of heavy atoms, and molecular complexity), $\mathrm{T}_{\mathrm{m}}$, $\log \mathrm{P}$, polar surface area (PSA), number of hydrogen bond donors and acceptors (HBD and HBA), and number of rotatable bonds (RotB). These physicochemical properties were analyzed from two different perspectives: (i) Lipinski's ruleof-five (Ro5) and (ii) molecular properties described above (brick-dust vs. grease-ball, GFA, and crystallization tendency). In short, according to Lipinski Ro5, poor intestinal permeation and/or poor solubility (and hence absorption) is expected from a compound with $\mathrm{MW}>500 \mathrm{~g} / \mathrm{mol}$, $\log \mathrm{P}>5, \mathrm{HBD}>5$, and $\mathrm{HBA}>10$ (66). We also included $\mathrm{T}_{\mathrm{m}}$ since a high $\mathrm{T}_{\mathrm{m}}$ has previously been negatively associated with GFA $(55,56)$.

Sixty-eight model compounds reported in 101 articles were analyzed with respect to chemical space. Most of the model compounds studied for amorphous formulation fell within the
Ro5 definition (Fig. 1). The increasing number of lead compounds falling outside the Ro5 chemical space (30) is clearly not mirrored in the scientific publications within this field. Among the articles reviewed, only $31 \%$ of the compounds were regarded as possibly poorly soluble by violating at least one of the Lipinski criteria. The Ro5 provides relatively general characteristics for compounds to predict good or poor absorption without specifying which formulation strategy is the best for any particular compound. For instance, the optimal formulation strategy will differ according to whether the compound has limited solubility or limited intestinal permeation as well as whether the compound is solid state-limited (brick-dust) or solvation-limited (grease-ball) in their solubility. An early understanding of which of these limitations is in play is therefore warranted. That allows appropriate, scientifically sound judgements to be made on which formulation strategies (i.e. which excipients, dosage forms, methods of preparation, etc.) should be used for a particular compound with known molecular properties and limitations. Subsequently, the performance (i.e. physical and chemical stability, dissolution, and intestinal permeation) of the selected formulation could also be properly understood (30,36,37,56,60,63,65,67-69).

Although amorphization as a formulation strategy could work for any group of compounds, the success of the formulation will nevertheless still depend upon inherent factors such as the physicochemical properties of the compounds. Fig. 1 shows that the compounds that were selected for amorphous formulation studies mainly fell within Lipinski Ro5 drug-like space; in that regard they were not model compounds of particularly problematic compounds. On the other hand, from the perspective of GFA and crystallization tendency (and thus stability), most of the studied compounds included in this review had properties that indicated good GFA, including high MW (>300 g/mol), a flexible molecular structure (indicated by a high number of RotBs), a high number of heavy atoms, and a reasonable number of HBDs. A high number of HBAs, a high PSA, and a high $\log \mathrm{P}$ appear to have a positive but small influence on amorphous stability according to the study by Nurzyn'ska and co-workers in 2015 (62). Although several studies have indicated similar molecular properties as being desirable for producing stable amorphous compounds $(56,60,62,63,65)$, applying strict cut-off values to differentiate between desirable and undesirable properties when predicting whether a poorly soluble compound would be a potential candidate for amorphous formulation should be made with caution. For example, experimental methods for determining GFA or crystallization tendency differ significantly, which could result in slightly different values. Furthermore, as shown in Fig.1, the relationships and interplay between the different physicochemical properties of the compounds are not always proportional, and hence they should be considered collectively rather than individually through the use of, for example, multivariate data analysis $(61,64,65)$. 
Fig. I Distribution of the physicochemical properties of model compounds: molecular weight (MW), melting point $\left(T_{m}\right)$, partition coefficient between octanol and water (LogP), polar surface area (PSA), number of hydrogen bond donors (HBD), number of hydrogen bond acceptors (HBA), and number of rotatable bonds (RotB).

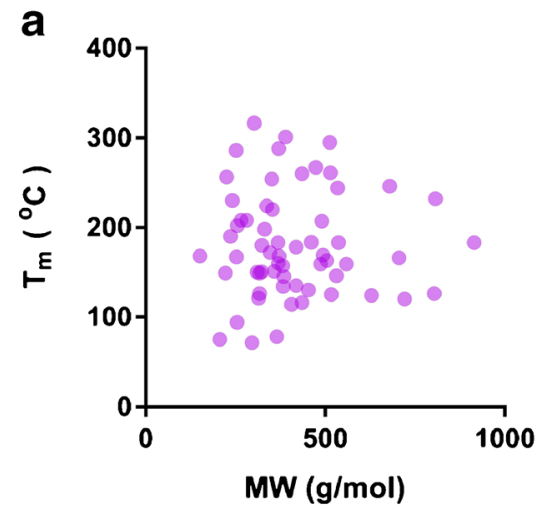

b
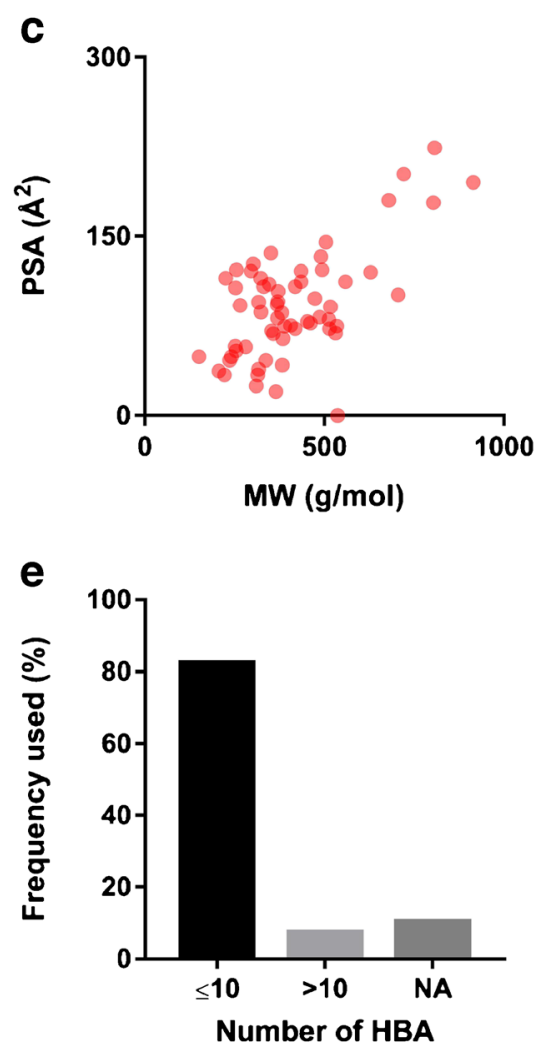
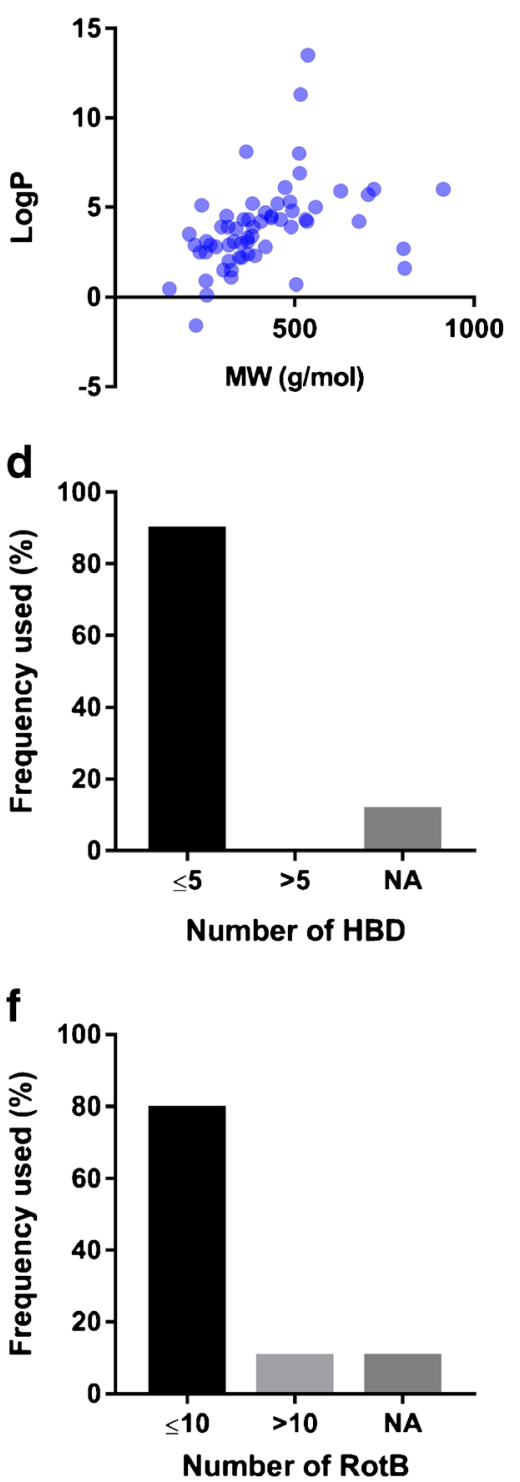

\section{Selection of Excipient}

According to the International Pharmaceutical Excipient Council, pharmaceutical excipients can broadly be regarded as any pharmacologically inert component of a pharmaceutical formulation that is not the active pharmaceutical ingredient (API) and that is added intentionally to the formulation. The excipients in pharmaceutical formulations can serve several purposes, including those related to processing, esthetic enhancement, optimization of product performance, and improvements in patient compliance (70).

Excipients are often required in amorphous formulations as amorphous compounds tend to be unstable on their own. The high free energy in the amorphous system is the driving force for the transformation of the compound to its more stable (low energy) crystalline form. However, there are currently no established recommendations on how to select the proper excipients for the formulation. Excipients are added at an early stage in the formulation design to inhibit or delay crystallization of the amorphous compound, which subsequently influences the physical stability, dissolution rate, extent of supersaturation and ultimately the bioavailability of the drug in vivo. Analysis of the articles included in this review revealed that several factors influence the choice of excipients for amorphous formulations; these were not only closely related to the relevant amorphous formulation per se, but were also related to the goals of the studies performed. 
Of the 101 articles reviewed, the motivation behind the addition of excipients was stated in $64 \%$, while the authors did not specify the reason(s) for selecting a certain excipient in the remaining articles (71-99). Some of the reasons given for excipient selection included reliance on previous reports of the use of similar excipients and their historical applicability in ASDs and oral dosage forms (100-125); the physicochemical properties and functions of the excipient, possible interactions between the compound and the excipient, and the miscibility/ immiscibility of the compound and excipient (105-108,111,112,114,126-148); the processability or suitability of the excipient for the preparation method (73,105,119,127,149-152); and the possibility of designing a controlled-release profile and/or $\mathrm{pH}$-dependent release of the compound from the amorphous formulation $(99,100,107,123,153-156)$. An attempt to tailor and customize excipients by modifying the functional groups which could be potentially used in ASD formulations has also been reported (157). In some other studies, more unconventional excipients were explored to investigate their potential use in oral pharmaceutical formulations, with limited reports on their inclusion in amorphous dosage forms (113,158-160). The excipients used in these cases were added for many different reasons, not only to provide amorphous stability (i.e. in the solid state and solution).

Despite the lack of any established and standard recommendations on excipient selections, several studies reported the use of theoretical and calculated mixing, miscibility and solubility parameters to determine drug-excipient miscibility and interaction. These are particularly used as a means to estimate the homogeneity of the mixture at a particular ratio, which is postulated to influence the stability of the resulted amorphous system. Among others, these include the calculation of the Hansen solubility parameters $(104,126,146,154,161)$ and the Flory-Huggins theory $(94,150)$.

The literature review also revealed that polymers were by far the most commonly used excipients for amorphous formulations, comprising $84 \%$ of all the reported excipients. The excipients reported in the reviewed articles are summarized in Fig.2. The polymer excipients were categorized into four groups: vinyl, cellulose, polyethylene oxide, and methacrylate and their derivatives. Vinyl and cellulose polymers were the most commonly used (35\% and $26 \%$, respectively), followed by polyethylene oxide (14\%) and methacrylate $(9 \%)$ polymers. The remaining $16 \%$ of the excipients used in amorphous formulations included surfactants, sugars, and alginates and derivatives thereof. These excipients were used either alone or in combination. When combined, the excipients were taken from different groups and normally served different functions aimed at improving the overall properties of the amorphous formulation. Generally, the amount of excipient and the excipient-to-compound ratio were based on the miscibility of

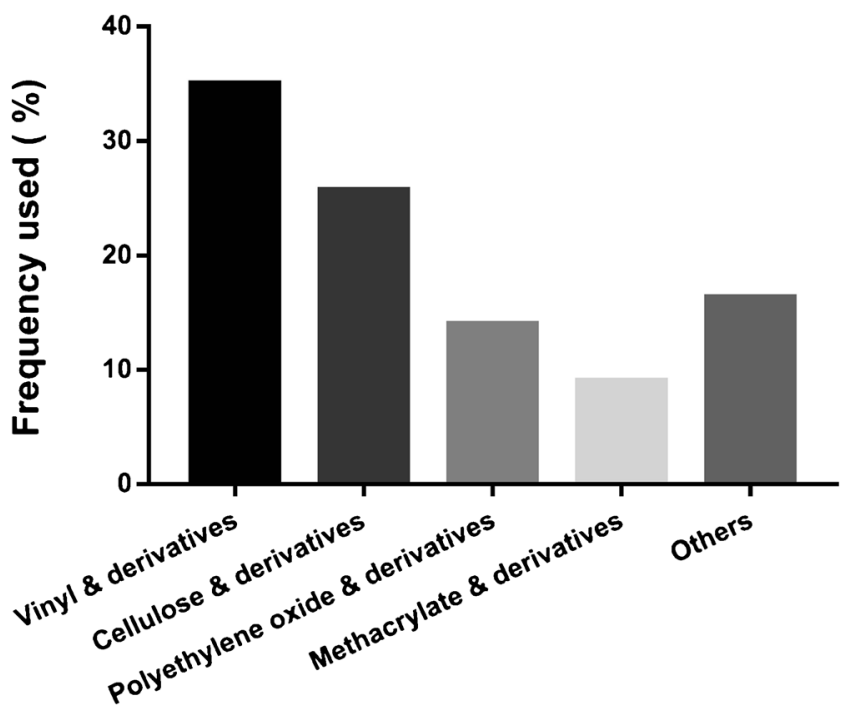

Excipient

Fig. 2 Excipient groups included in amorphous formulations.

the excipient with the compound and the ratio that would provide the best dissolution profile and/or stability performance $(71,99,125-127,144,159,162)$.

\section{Selection of Preparation Method}

Amorphization can be achieved via several different preparation techniques. These techniques can be classified as solventbased, temperature-based (fusion) and mechanical-based (activation); sometimes these methods are used in combination. Solvent-based methods include spray-drying, freeze-drying, precipitation, solvent evaporation, use of a confined impinging jet reactor, supercritical fluid methods, and different types of electro-spraying; temperature-based methods include the classical melt-quenching/quench-cooling methods and hot-melt extrusions. Various milling techniques were herein categorized as mechanical-based. Some preparation methods that have been combined to achieve amorphization include hot-melt extrusion and electrospinning and solventantisolvent precipitation and sonication (sonoprecipitation). Fifty-six percent of the reviewed methods used in preparing amorphous formulations were solvent-based, while 35\% were temperature-based. Only 7\% were mechanical-based and $2 \%$ used a combination of two methods (Fig. 3). Most of the methods reported in this review were used at a laboratory scale for research purposes. From a pharmaceutical industry perspective, spray-drying and hot-melt extrusion are the most common methods of preparation, as reflected in the preparation methods reported for the marketed amorphous drug formulations $(163,164)$. The broad use of a spray-drying technique may be due to the fact that it is relatively easy to scale this method to industrial settings, and to apply it to a wider range of physicochemical properties, especially for 


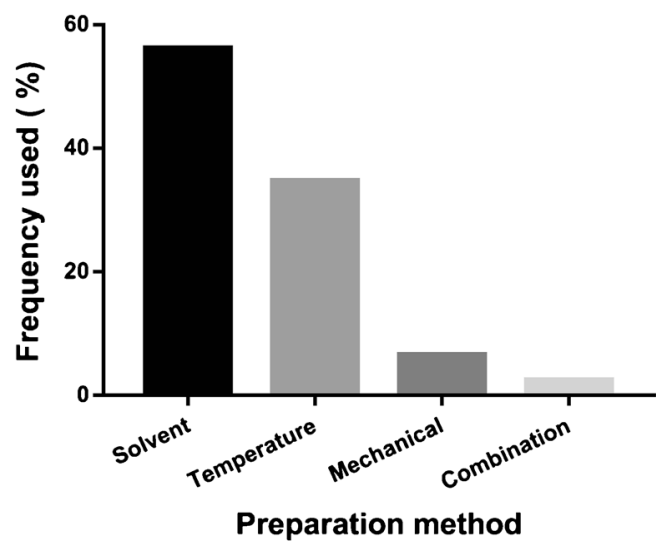

Fig. 3 Methods of preparing amorphous formulations.

compounds with thermal and shear instability. In addition, the method is material-sparing compared to other methods and this attracts formulation scientists to use laboratory-scale spray drying in the early development phase when the amount of material available may be limited (165-167).

Beside reviewing different amorphization methods, we also wanted to investigate whether there is any relationship between selection of the preparation method and the physicochemical properties of the compounds. The results of this analysis are summarized in Fig. 4. A trend was observed with the temperature-based and solvent-based methods, but not with mechanical-based and combined preparation methods, probably because of the limited number of studies where these methods were used. The choice of solvent-based methods was made across a slightly wider distribution of $\mathrm{MW}, \mathrm{T}_{\mathrm{m}}$ and $\log \mathrm{P}$ than seen with temperature-based methods. This was based on analysis of the single properties (Fig. 4) as well as the principal component analysis (data not shown). It does make sense that the solvent-based methods, which typically use water and/or organic solvents with variable dielectric constants ranging from relatively polar (e.g. methanol) to non-polar (e.g. hexane or mixtures of solvents), have the capacity to handle compounds with a wide range of lipophilicity. The trend for the temperature-based methods to be somewhat less applicable to the typical brick-dust molecules $\left(\mathrm{T}_{\mathrm{m}}>200^{\circ} \mathrm{C}\right)$ is probably the result of the increased risk of chemical degradation when using the required high temperature. For other physicochemical properties (number of rotatable bonds, hydrogen bond capacity, molecular complexity) there was no clear trend for predicting the method.

Finally, we investigated the extent to which different excipients were used in the various preparation methods, focusing on polymers commonly used in amorphous formulations. Because the role of the excipients in the reviewed amorphous formulations was not limited to stabilizing the amorphous form, and because the roles were not specified in the reviewed articles, this was difficult to analyze (Fig. 5) (71-85,87,88,90-139,141-161,166,168-177). The polymers were most commonly $(62 \%)$ used in solvent-based methods. This finding parallels our earlier observation that there is wide usage of solvent-based methods in the preparation of amorphous formulations. Vinyl (31\%) and cellulose $(29 \%)$ polymer derivatives were the most common choice for solvent-based methods, followed by polyethylene oxide derivatives $(12 \%)$ and methacrylate polymers $(9 \%)$. For the temperature-based methods, the vinyl derivatives were the most commonly used $(42 \%)$, followed by cellulose derivatives $(21 \%)$, polyethylene oxide derivatives $(18 \%)$, and methacrylate polymers $(10 \%)$. Mechanical-based methods commonly used vinyl polymers $(50 \%)$, followed by cellulose $(17 \%)$ and methacrylate $(8 \%)$ polymers. The mild conditions associated with solvent-based methods (i.e. relatively lower temperature and mechanical activity) compared to temperature-based and mechanicalbased methods make them more flexible in terms of selecting the best compound and excipient, as long as both components are miscible and soluble in the solvent system used. However, more stringent criteria are required for temperature-based methods, including criteria for the $\mathrm{T}_{\mathrm{g}}$ and the $\mathrm{T}_{\mathrm{m}}$ of both the compound and the excipient, the viscosity of the excipient, the miscibility of the components, the extrudability of the mixture, and the potential degradation of the compound on exposure to high temperature during the process $(74,76,103,109,129,138,150,155,175)$. These could limit the applicability and use of temperature-based methods in the preparation and study of amorphous formulations.

Recently, reports on a novel processing technology based on temperature and high shear force mixing have shown potential in overcoming the limitations associated with conventional hot-melt extrusion and spray-drying techniques $(143,147,151)$. More uncommon preparation methods which are not widely used and established industrially for the preparation of amorphous formulations such as supercritical fluid impregnation /solvent-antisolvent (84,92, 102,149), electrospinning /electrospraying $(72,91,141,153,174)$, confined impinging jet (107) and pressurized gyration (161) have also been explored even though the applicability in large scale is still a question.

\section{Methods of Assessing the Performance of Amorphous Formulation}

Amorphous material is thermodynamically unstable, with an inherent tendency to return to its more stable crystalline form. In order to ensure that developing an amorphous drug formulation is a viable strategy for improving solubility, the stability of the formulation in the solid state (physical) and in solution (supersaturation) must be examined. If crystallization occurs during storage, the solubility and dissolution advantages obtained from the amorphous formulation will be lost. In the reviewed articles, despite the pharmacopoeia and international harmonization initiative providing guideline methods for 
Fig. 4 Relationship between the physicochemical properties of the model compounds and the chosen amorphous formulation preparation method: solvent-based ( $\boldsymbol{\square})$

temperature-based $(\mathbf{O})$

mechanical-based $(\boldsymbol{\Delta})$ and combination $(\nabla)$. MW molecular weight,

$T_{m}$ melting point, $\log P$ partition coefficient between octanol and water, PSA polar surface area, $H B D$ number of hydrogen bond donors, HBA number of hydrogen bond acceptors, RotB number of rotatable bonds. a

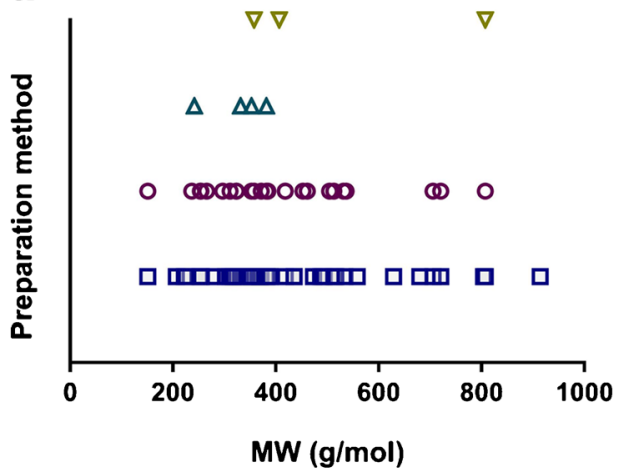

C

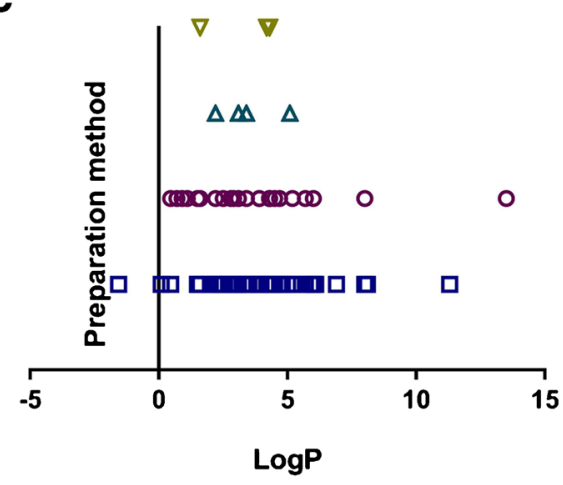

e
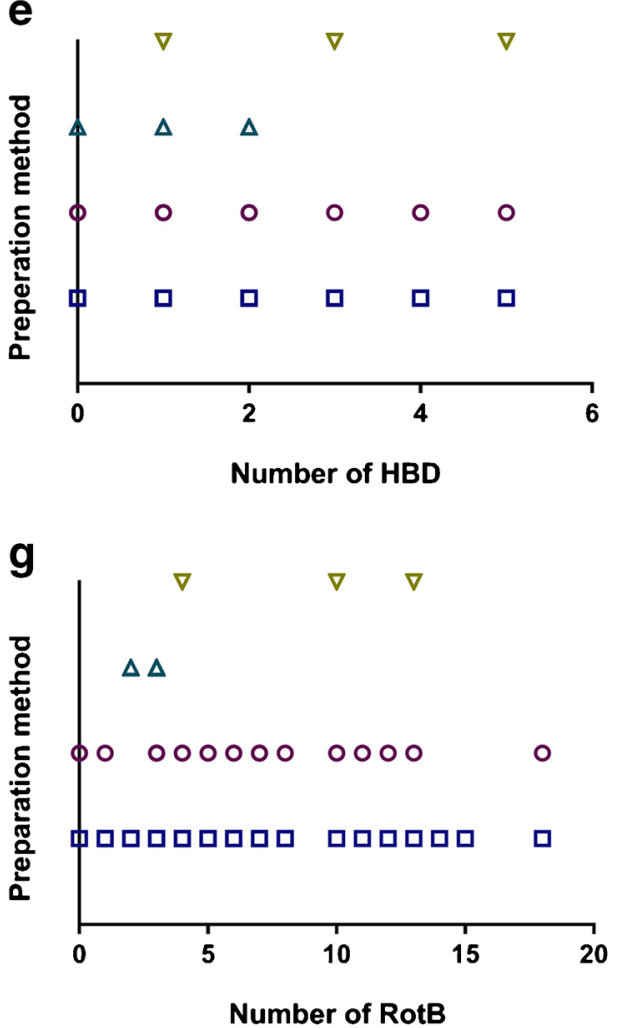

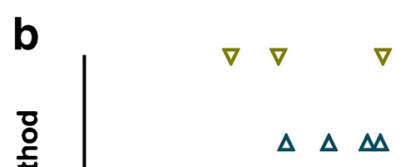

- 0 coreces 000

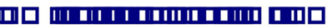

ำ

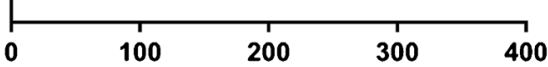

$\mathrm{T}_{\mathrm{m}}\left({ }^{\circ} \mathrm{C}\right)$

d

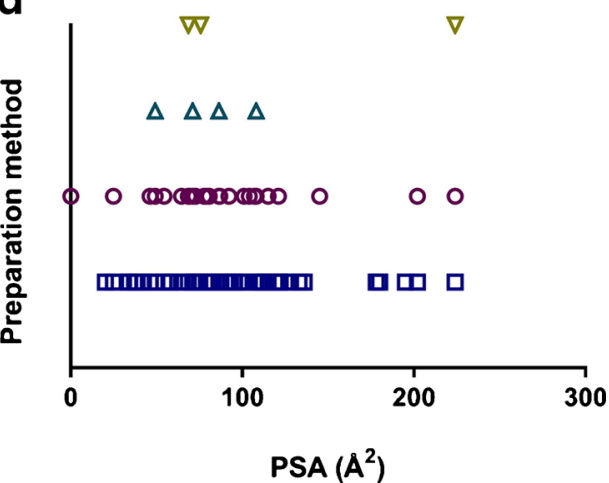

f

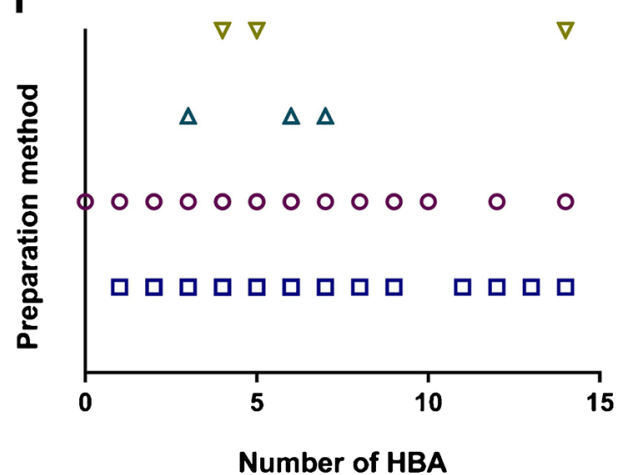

stability studies for any dosage form, the conditions and durations selected for the physical stability studies of amorphous formulations were surprisingly diverse. The temperatures ranged from $2^{\circ} \mathrm{C}$ to $60^{\circ} \mathrm{C}$ and the relative humidity varied 
Fig. 5 Distribution of excipients used in the different methods of preparing amorphous formulations.

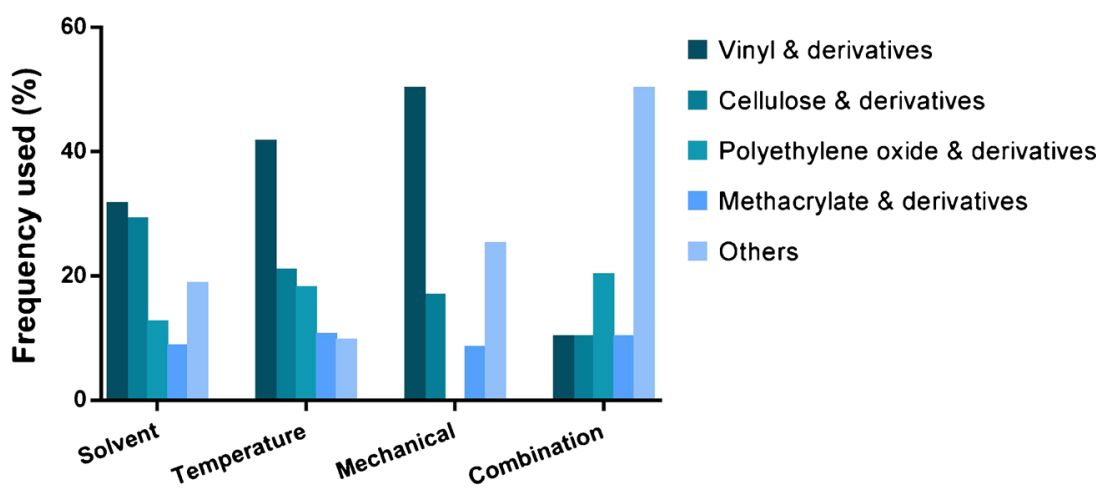

Preparation method between $0 \%$ and $100 \%$. The duration also varied significantly, with stability studies lasting from $24 \mathrm{~h}$ to two years $(73,74,81,82,84,86,88,92,93,104,105,109,110$, $113,115,116,118,120,123,124,126,127,129,130$, $132,134,135,139,143,146,149,153,158,166$, $169,172,175,176)$. While most of the studies did not mention the container used for the physical stability test, a few specified, for example, whether a closed or open container was used $(88,92,113,123,132,146)$. Of these six articles that mentioned whether closed or open container was used, only one specifically reported the type of container used (i.e. high density polyethylene bottle) in the stability study (132) whereas the remaining studies mentioned only that tube (88), airtight brown vial (92), vial (113), sealed aluminum strip (123) or sealed glass container (146) was used. These large variations in the design of stability studies make direct comparison impossible, since the stability profile obtained is specific only for the stability method employed. Hence, what was regarded as a stable amorphous formulation in one study may not be stable in another. While the stability tests in the reviewed articles may have been designed to answer a particular research question, it would of course be beneficial for the research field if these studies also were performed using more standardized methods (USP) and/or follow the universally harmonized guidelines. Information could then be extracted about the molecular processes involved in the loss of the (solid) amorphous form.

Solubility and in vitro dissolution studies are also conducted to assess the performance of an amorphous formulation. In the reviewed articles, no specific method was used in the investigation of amorphous solubility and dissolution behavior, even though different pharmacopoeia methods provide general guidance on how they should be performed. Ninety-two of the 101 studies reported solubility and dissolution studies (71-74,77-79,81-92,95,97-107,109-111,113-119,121,123,124,126-133,135-139,141-154,156,157,160,161,166,168-176). The USP in vitro dissolution type II apparatus was the most commonly used instrument (67\%), followed by the USP type I apparatus (6\%), while the remaining $27 \%$ used various other apparatuses, including modified versions of the USP type I only (148) or paired with confocal Raman microscopy (98), USP types I and II apparatus (72), USP type IV (152), closed loop of USP types II and IV (152), a perspex flow cell $(73,142)$, a rotary mixer (131), a Chinese pharmacopoeia type III apparatus (118), an in-house miniaturized USP type II apparatus (175), Sirius T3 apparatus (146), $\mu$ FLUX dissolution-permeation apparatus (141), Raman UV-Vis flow cell system (99), a centrifuge (88), high throughput screening using a 96-well plate $(82,115,157)$, Wood's apparatus (99,137), an orbital shaking incubator (156), and another shake-flask method (171) (Fig. 6). In several of these studies, dissolution apparatuses were either modified, optimized or paired with other instruments and methods to enable the investigation, monitoring, and understanding of other processes that take place concurrently with dissolution such as permeation (141), release mechanisms $(73,98,99,101,106,142)$ and wetting kinetics (71). The experimental conditions during in vitro dissolution testing (e.g. type of medium, medium volume, temperature, $\mathrm{pH}$, and sink/non-sink conditions) also varied. The majority of the studies used a large volume of medium $(\geq 250 \mathrm{ml})$, which can indirectly be translated to the equally large amounts of materials required in practice. Depending on the condition selected (sink or non-sink), weight of samples between 5-1800 mg were reported

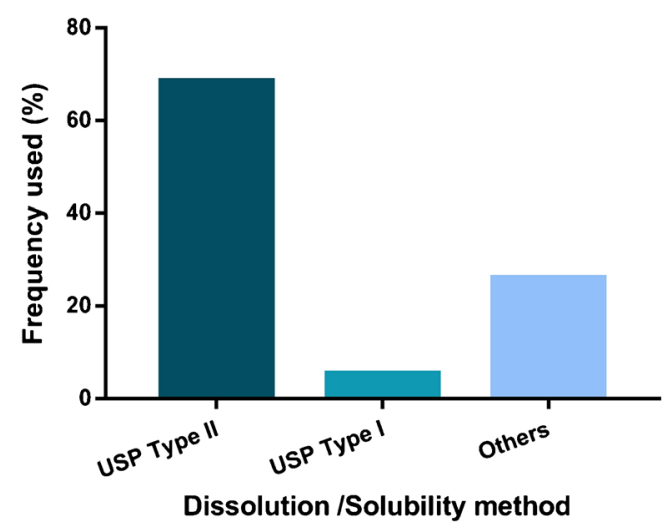

Fig. 6 In vitro dissolution apparatuses used in the reviewed studies. 
(72,74,77-79,83-85,87,90,91,95,100,105,106,109-111,114,$116,121,126,128,130,135,136,138,149,154,166,170)$. Interestingly, the use of small-scale or miniaturized in vitro dissolution methods is still limited. Likewise, the media reported were mainly different types of a simple buffers such as treated water (i.e. deionized, degassed, distilled, purified), $\mathrm{HCl}$, and phosphate/acetate buffers at $\mathrm{pHs}$ ranging from 1.2 to 7.4 (71-74,77-79,81-88,90-92,95,100-107,109-111,113-119,121,126,127,129-133,135-139,149,150,153,154,156,160,161,166,168-177). Among the 88 studies that reported a dissolution assay, only sixteen $(\sim 18 \%)$ used a biorelevant dissolution medium (BDM) such as simulated gastrointestinal fluids and simulated saliva $(77,79,82,97,121,123$ ,130,135,136,145,152,154,160,169,170,176). These disparities in medium used affect the conclusions, which (as with the stability studies) make head-to-head comparison difficult. The choice of solubility and dissolution methods was possibly partly driven by the general goals of the studies performed.

\section{THE NEED FOR METHODS TO BETTER UNDERSTAND THE PROCESSES OCCURRING DURING THE PREPARATION, STORAGE AND DISSOLUTION OF AMORPHOUS DRUGS}

Our analysis of articles on amorphous compounds published 2011-2016 indicates that knowledge of when to use specific methods or excipients to produce a well-functioning delivery system based on the amorphous form is still limited. One reason for this limited knowledge is simply the low number of compounds that have been studied. Typically, each study investigated only one or at best a few compounds and the general applicability of the conclusions drawn cannot therefore be validated. More than $65 \%$ of the studies focused on the development stage rather than the research stage of the R\&D process and seemed to be aiming to quickly assess the development potential of an amorphous form of a particular compound (Fig. 7). Encouraging is however that there has been a tremendous increase in research-based studies reported in 2016 which are included in this review $(61 \%)$, an indicator that there is an increased awareness within the scientific community on the better understanding of amorphous-based formulation which performance is influenced by complex interplay between multiple factors. We would like to emphasize the importance of increasing the focus on the research stage so as to increase understanding of when amorphization should be targeted for a new compound. A scientific rationale needs to be developed to guide the choice of methodology and excipients for any new compound (rather than just starting to explore a number of excipients and methods).

In a recent study by Edueng et al., an experiment-based road map for delineating the need for stabilization of the amorphous form dissolved in water was developed (177).
The experimental set up was designed to show whether the compound had solid-to-solid or solution-mediated crystallization, with the aim of clarifying whether stabilizers should be included in the solid amorphous material or whether a simple physical mixture with, for example, polymers would be enough to maintain supersaturation when the material was exposed to water. The method was based on a number of solid-state and dissolution characterization methods, all of which used small amounts of compound to measure the response. A solvent-based method (spray-drying) was used to prepare the material, but other methods could potentially have been used to produce the amorphous form. However, based on our analysis of method selection in this paper, which indicates that the solvent-based method seems to be more generally applicable from a compound perspective, it makes sense to start with any of the solvent-based method such as spray-drying, solvent evaporation or freeze drying when aiming for an amorphous formulation. In the study by Edueng and coworkers, spray-drying was the method of choice due to its established applicability in the production of amorphous compounds and/or ASD both in laboratory and industrial scale (177). The experimental road-map is one way of increasing the throughput of compounds being explored. The process allows larger datasets to be studied and these are expected to provide a scientific basis for better understanding the mechanisms of, for example, crystallization and stabilization of the amorphous material. Further, if structurally diverse datasets are explored, it will be possible to extract general information about these processes, which would help to guide the development of future amorphous formulations of any new compound that is in need of increased solubility or dissolution in order to be orally administered.

\section{Assessment of glass-forming ability: new experimental and computational methods}

GFA and crystallization tendency have recently been explored computationally using a number of models based on multivariate data analysis (as described in the "selection of model compound" section). The large datasets studied and multivariate data analysis such as partial least square analysis and support vector machines have allowed discrimination between glass formers and non-glass formers, and even between compounds with rapid or slow crystallization rates in the solid form, based on calculated molecular descriptors obtained from a 2D or 3D chemical structure (60,63-65). Models which can predict the $\mathrm{T}_{g}$ have also been described recently (178). These models are useful in the early stages of formulation design for indicating whether amorphization of a new compound is likely to be successful and the extent to which stabilization of the solid form might be required.

Recently, Blaabjerg and coworkers suggested the use of time-temperature-transformation (TTT) diagrams for 

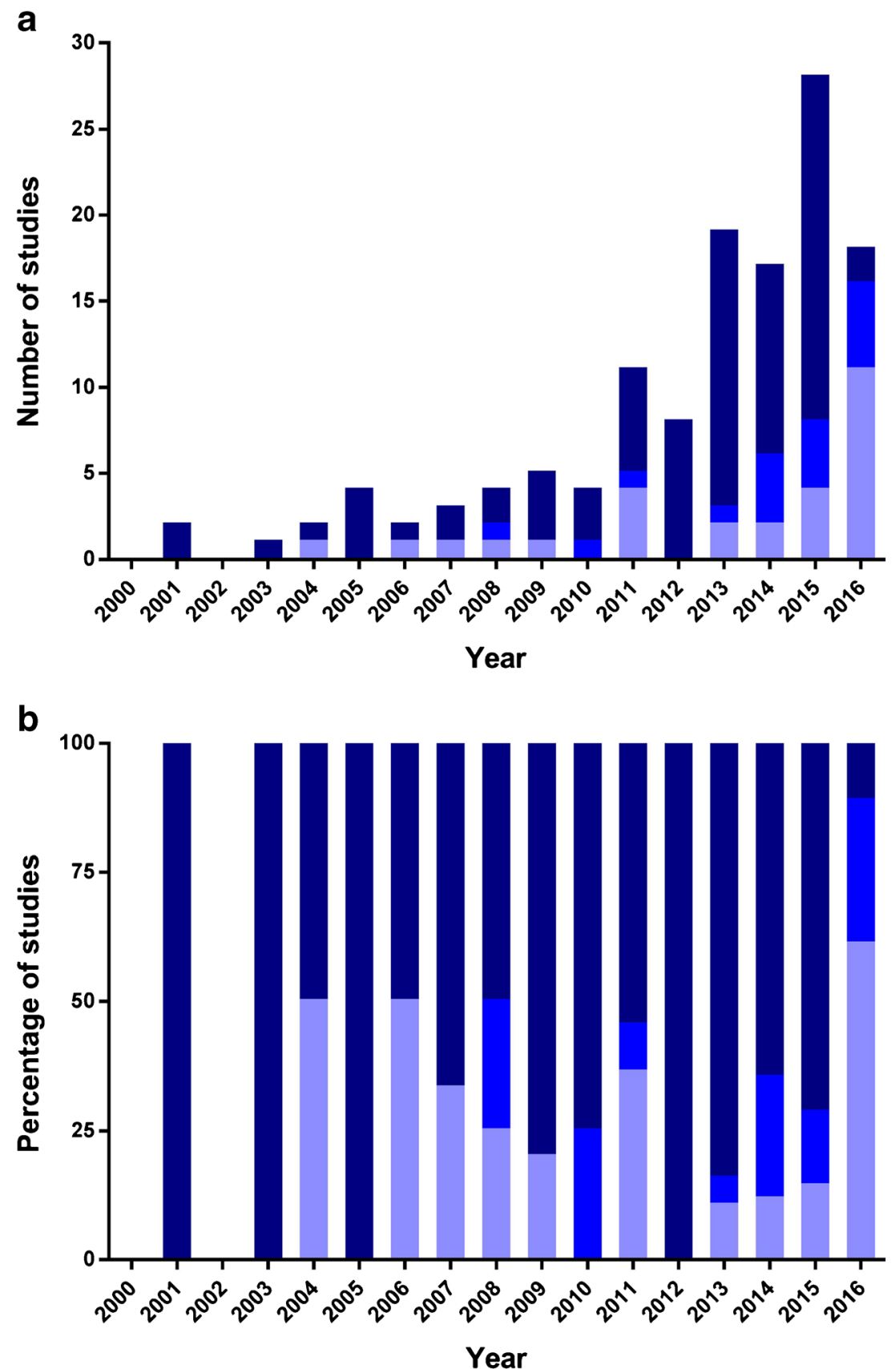

Fig. 7 The (a) number and (b) percentage of amorphous drug-based studies reported between 2000 and 2016 that focused on research ( ), a combination of research and development $\square$, or development

identifying the GFA (179). While all compounds are theoretically able to transform into their amorphous form given optimal experimental settings, in this method the GFA is based on the cooling rate that is needed to produce the amorphous form. Based on experimental data for 12 compounds they suggested that compounds that are extremely difficult to make amorphous (and which in the computational work mentioned above would be defined as non-glass formers) require cooling rates $>750^{\circ} \mathrm{C} / \mathrm{min}$. Glass formers were then divided into those requiring modest cooling rates $\left(>10^{\circ} \mathrm{C} / \mathrm{min}\right.$; the rate typically seen in standard melt-quenching methods) and those requiring low cooling rates $\left(>2^{\circ} / \mathrm{min}\right)$; these compounds should be easily transformed to the amorphous form and hence are ideal compounds for this formulation pathway (179). An efficient work flow for this pathway would be to identify glass formers using a computational model and then to verify the prediction using the TTT method.

\section{Some New Insights to the Phase Behavior of ASDs}

The possibility to experimentally assess drug-polymer miscibility has been dependent on the development of new high- 
resolution techniques for detection of small phase domains in amorphous solids. Beside the scanning probe based imaging techniques, (180) NMR has been proven as a powerful tool for identifying domains in phase separated amorphous solids down to a few nanometer in size $(162,181)$. The relationship between thermodynamic miscibility, phase separation and crystallization of ASDs are however not yet fully clarified.

On the other hand, new insights to the phase behavior of drugs in supersaturated solutions generated during dissolution of ASDs have recently been provided by Taylor and coworkers. The formation of sub-micron particles of felodipine and indomethacin was observed during dissolution of ASDs which distorted UV-probe measurements leading to the detection of falsely high free drug concentrations (182). In later publications liquid-liquid phase separation was proven to occur upon precipitation, which occurs at concentrations exceeding the solubility of the amorphous form of a drug (168). This underpins that a thorough understanding of the phase behavior during dissolution of these types of systems is crucial for rational selection of formulation and assessment techniques for ASDs.

\section{Computational Simulations of Amorphous Drugs, Amorphous Solid Dispersions, and Supersaturation}

While the experimental road-map established by Edueng et al. reveals the effect of water as a plasticizer of the amorphous form and the extent to which supersaturated aqueous systems are prone to nucleate and crystallize, advanced computational models can also be used to study amorphous compounds and their formulations (177). During recent years, molecular dynamics (MD) simulations have been used to study the GFA, the characteristics of the amorphous form itself, the interaction between the compound and water, and the possible crystallization of the compound from supersaturated solutions. MD simulation is a powerful computational technique that can reveal inter- and intra-molecular interactions at a detailed level. Depending on the resolution of the simulation, the length-scale and the physical volume that can be explored may vary; the most computer-demanding all-atom simulations are typically used to study simulation boxes of $\sim 10 \mathrm{~nm}$ (each side) for $100 \mathrm{~ns}$, whereas the less resolved, coarse-grained method is used for boxes of $\sim 50 \mathrm{~nm}$ (each side) for microseconds. Both of these methods have their place; however, most studies so far have used the all-atom resolution. It should be mentioned that although this methodology is beginning to be applied in studies of amorphous drug systems, it is still only used in relatively few studies and is not used to the same extent as in material sciences and cell biology studies. Some of these studies are outlined in the following section to provide a glimpse of the level of information that can be expected from these simulations.

\section{Molecular Dynamics (MD) Simulations of Amorphous Drugs, Amorphous Solid Dispersions, and Crystallization from Supersaturation}

MD simulations have been used by Xiang and Anderson to study the characteristics of amorphous indomethacin with and without stabilizing polymers $(89,183)$. They also performed MD simulations for polymers such as hypromellose acetate succinate and poly-lactide (184,185). The investigations used dry amorphous indomethacin, as the simulation only used $0.6 \%$ w/w water molecules (183). The system was quickly equilibrated to a high temperature $(10 \mathrm{~ns}$ at $600 \mathrm{~K}$ and 1 bar under periodic boundary conditions) after which it was cooled to $200 \mathrm{~K}$ using a cooling rate of $0.03 \mathrm{Kps}$. This procedure mimicked the setup for melt quenching; however, the rate of cooling was much higher in the simulations than what is possible to achieve experimentally. As a consequence, the $\mathrm{T}_{\mathrm{g}}$ in the simulations deviated significantly from those determined experimentally ( $64 \mathrm{~K}$ higher). However, dynamic properties such as density, water diffusion in the material, and the rotational relaxation of indomethacin were in good agreement with the experimental data. It was also found that the hydrogen bond pattern in amorphous indomethacin was highly complex, which is in agreement with spectroscopic data of amorphous indomethacin. In the subsequent study they investigated the interaction between indomethacin and PVP, using the simulations to aid, for example, investigation of the miscibility of the drug and the excipient. The importance of the interactions between the compound and the polymer were also analyzed, and it was found that PVP stabilized the indomethacin via formation of hydrogen bonds (89). Fule and Amin also used MD simulations to explore the stabilizing effect of polymers in the solid form (186). They studied the interaction between posaconazole and a number of different excipients, using the monomer form of the polymers investigated. For each of the drug-polymer systems, the strength of the bonds between the drug and the polymer was used to indicate the stabilizing effect of the polymers. The most stable system in the MD simulations was also the highest ranked formulation in in vitro and in vivo dissolution tests, although the experimental data did not provide a statistical analysis.

Mesoscale dissipative particle dynamic (DPD) simulations can be used to computationally explore the movement of long polymer chains over relatively long time spans $(187,188)$. This method was recently used to study the performance of a $20 \%$ lacidipine (BCS II drug)-loaded ASD stabilized by Eudragit E 100 when exposed to $\mathrm{pH} 1.2$ and $\mathrm{pH} 6.8$ dissolution tests (189). A large number of experimental techniques were used to characterize the ASD and the data analysis was complemented with a DPD simulation to investigate the 
experimental observations at a molecular level. The DPD simulation facilitated insight into the miscibility of the included components and the effects of $\mathrm{pH}$ on the miscibility of, for example, the drug and water or the polymer and water. It was also demonstrated that swelling of the polymer was important for increasing the release of lacidipine. Overall, the DPD simulation allowed the successful study of the microscale properties (i.e. miscibility, swelling, drug release) although the molecular interaction pattern was not revealed at the low resolution used. For that purpose other simulations with increased resolution, e.g. at the all- or united-atom level, are needed.

Nucleation and crystal growth from a supersaturated solution have also been studied using MD simulations (190). Investigation of the impact of the supersaturation level on the second nucleation of bicalutamide (a BCS class II drug), i.e. nucleation after introducing a bicalutamide crystal to seed production of a particular polymorph, revealed that the second crystallization occurred in the supersaturated solvent at high supersaturation levels. This is to be expected, as the chemical potential of the system would have driven homogeneous crystallization to occur. In contrast, crystallization occurred on the surface of the seed crystal when the supersaturation level was low. This too is expected, since the concentration was too low to cause the significant aggregation needed to form the crystal nuclei in the solution. The crystallization occurring at intermediate supersaturation levels was a mixture of these two processes. Solubilized aggregates of the drug were formed in the intermediate supersaturated solution and these crystallized when they came into contact with the seed crystal. The "second" crystal was then able to detach from the crystal seed surface because of the weak bonding forces and small areas of contact between the flat seed crystal and the curved aggregate that crystallized. Once the crystals had detached they could induce crystallization of the solubilized aggregates when these collided in the solution, acting as second seed crystals in the solution.

\section{SUMMARY}

The field of amorphous drug formulations needs to move from being descriptive science to becoming predictive science. It is clear from this review that most of the recent publications on amorphous dosage form design and selection of excipients were still focusing on development, although the papers published during 2016 were indeed more research focused than those published 2011-2015. It may be acceptable for industrial-based studies to focus on the development stage, but academic institutions need to set the science first. To develop the field further, researchers need to ask (and try to answer) the difficult, but crucial, questions related to the mechanisms and processes involved in the performance of the formulation. The research-based and development-based practices within these different sectors (academic and industry) should be complementary in nature, in order not to unnecessarily replicate studies already done, thus accelerating the whole developmental process. The recent advances in technology, including highly sensitive experimental techniques (based on spectroscopy, microscopy, scattering, or thermal techniques) and computational methods (quantitative structure property relationships obtained via multivariate data analyses of varying complexity and $\mathrm{MD}$ simulations), should be used together to tackle processes that we still poorly understand. If these processes were better understood, the probability of developing a well-functioning ASD at the first attempt might be significantly increased. Some of the crucial processes that merit further attention and significant effort to increase the understanding of these complex formulations are outlined below. It is suggested that successful research in this field would consequently be rapidly translated into the development setting.

- Processes occurring at the particle surface during storage (at interfaces exposed to varying temperatures and humidity) and during dissolution (at the particle-water interface) merit further attention. In particular, we need studies of:

- diffusion of water through the amorphous form and the effect of water on relaxation and nucleation kinetics,

- the effect of elevated temperature and its relationship to the kinetics of nucleation,

- the likelihood of a highly viscous interface forming between a solid amorphous material and water during dissolution and the potential effect of this on release and nucleation kinetics,

- nucleation occurring in the highly concentrated microclimate surrounding the amorphous particle during dissolution.

- Insights into the molecular interactions between the drug and the polymer in the solid material, as well as during dissolution, are crucial in order to arrive at a scientific rationale as to why a certain polymer is successful. These studies require large numbers of drugs and polymers and varying conditions, and would benefit from an experimental design approach where combination effects can be more easily identified. Further, the obtained data could be used to produce models of a more general applicability. The key to success is to take a global approach, where head-to-head comparisons can be performed between different drugs and polymer systems. Hence, the field needs to move away from case studies, which often explore either reference (model) compounds or polymers that have been repeatedly used in the scientific literature.

- Dissolution/release and nucleation/crystal growth processes under physiologically relevant conditions need attention to understand the interplay between the compound and the excipients of the ASD and the naturally present (soluble) lipoidal nanoaggregates. This area needs 
standardization to make use of data generated by different laboratories. Further, dissolution experiments performed in combination with permeability assessments, as suggested by, for example, Yamashita and colleagues, would reveal the extent to which the release of drug from ASDs is directly related to increased absorption (and, hence, could be expected to increase the bioavailability), and should also increase understanding of the in viwo processes driving absorption (191).

These processes are already being addressed in some laboratories. However, we are emphasizing the need for a more holistic approach, in which a combination of experimental data, theory, and computational simulations are the cornerstones of each research project, in an effort to extend the borders of research on amorphous pharmaceutical materials. The field needs larger databases on the properties of amorphous compounds and the associated formulations, which include data that have been determined by sensitive but standardized methods. In addition, scientists need to challenge themselves, and the field, by asking the truly difficult questions related to amorphous formulations, moving from the comfort zone we are currently in. If this can be achieved, we will start to reveal the mysteries around the nucleation process that takes place when ASDs are exposed to water, the interplay between the water, the drug, and the excipient, and the supersaturation levels and absorption achieved in vivo.

\section{ACKNOWLEDGMENTS AND DISCLOSURES}

This work was supported by the European Research Council Grant 638965 and the Swedish Research Council Grant 2014-3309. The Ministry of Higher Education and International Islamic University, Malaysia are acknowledged for the financial support provided for the author, Khadijah Edueng.

Open Access This article is distributed under the terms of the Creative Commons Attribution 4.0 International License (http://creativecommons.org/licenses/by/4.0/), which permits unrestricted use, distribution, and reproduction in any medium, provided you give appropriate credit to the original author(s) and the source, provide a link to the Creative Commons license, and indicate if changes were made.

\section{REFERENCES}

1. Simonelli AP, Mehta SC, Higuchi WI. Dissolution rates of high energy polyvinylpyrrolidone (PVP)-sulfathiazole coprecipitates. J Pharm Sci. 1969;58:538-49.

2. Mayersohn M, Gibaldi M. New method of solid-state dispersion for increasing dissolution rates. J Pharm Sci. 1966;55:1323-4.
3. Bates TR. Dissolution characteristics of reserpinepolyvinylpyrrolidone co-precipitates. J Pharm Pharmacol. 1969;21:710-2.

4. Goldberg AH, Gibaldi M, Kanig JL, Mayersohn M. Increasing dissolution rates and gastrointestinal absorption of drugs via solid solutions and eutectic mixtures IV. J Pharm Sci. 1966;55:581-3.

5. Mullins JD, Macek TJ. Some pharmaceutical properties of novobiocin. J Am Pharm Assoc Am Pharm Assoc. 1960;49:245-8.

6. Sekiguchi K, Obi N. Studies on absorption of eutectic mixture. I. A comparison of the behavior of eutectic mixture of sulfathiazole and that of ordinary sulfathiazole in man. Chem Pharm Bull. 1961;9:866-72.

7. Chiou WL, Riegelman S. Pharmaceutical applications of solid dispersion systems. J Pharm Sci. 1971;60:1281-302.

8. Chiou WL, Riegelman S. Preparation and dissolution characteristics of several fast-release solid dispersions of griseofulvin. J Pharm Sci. 1969;58:1505-10.

9. Forster A, Hempenstall J, Rades T. Characterization of glass solutions of poorly water-soluble drugs produced by melt extrusion with hydrophilic amorphous polymers. J Pharm Pharmacol. 2001;53:303-15.

10. Forster A, Hempenstall J, Tucker I, Rades T. Selection of excipients for melt extrusion with two poorly water-soluble drugs by solubility parameter calculation and thermal analysis. Int $\mathrm{J}$ Pharm. 2001;226:147-61.

11. Forster A, Hempenstall J, Rades T. Comparison of the GordonTaylor and Couchman-Karasz equations for prediction of the glass transition temperature of glass solutions of drug and polyvinylpyrrolidone prepared by melt extrusion. Pharmazie. 2003;58: 838-9.

12. Alleso M, Chieng N, Rehder S, Rantanen J, Rades T, Aaltonen J. Enhanced dissolution rate and synchronized release of drugs in binary systems through formulation: amorphous naproxencimetidine mixtures prepared by mechanical activation. J Control Release. 2009;136:45-53.

13. Laitinen R, Lobmann K, Strachan CJ, Grohganz H, Rades T. Emerging trends in the stabilization of amorphous drugs. Int $\mathrm{J}$ Pharm. 2013;453:65-79.

14. Löbmann K, Strachan C, Grohganz H, Rades T, Korhonen O, Laitinen R. Co-amorphous simvastatin and glipizide combinations show improved physical stability without evidence of intermolecular interactions. Eur J Pharm Biopharm. 2012;81:159-69.

15. Doherty C, York P. Evidence for solid- and liquid-state interactions in a furosemide-polyvinylpyrrolidone solid dispersion. J Pharm Sci. 1987;76:731-7.

16. El-Hinnawiand MA, Najib NM. Ibuprofen-polyvinylpyrrolidone dispersions. Proton nuclear magnetic resonance and infrared studies. Int J Pharm. 1987;37:175-7.

17. Taylor LS, Zografi G. Spectroscopic characterization of interactions between PVP and indomethacin in amorphous molecular dispersions. Pharm Res. 1997;14:1691-8.

18. Yoshioka M, Hancock BC, Zografi G. Crystallization of indomethacin from the amorphous state below and above its glass transition temperature. J Pharm Sci. 1994;83:1700-5.

19. Andronis V, Zografi G. The molecular mobility of supercooled amorphous indomethacin as a function of temperature and relative humidity. Pharm Res. 1998;15:835-42.

20. Oksanen CA, Zografi G. The relationship between the glass transition temperature and water vapor absorption by poly(vinylpyrrolidone). Pharm Res. 1990;7:654-7.

21. Hancock BC, Zografi G. The relationship between the glass transition temperature and the water content of amorphous pharmaceutical solids. Pharm Res. 1994;11:471-7.

22. Hancock BC, Shamblin SL, Zografi G. Molecular mobility of amorphous pharmaceutical solids below their glass transition temperatures. Pharm Res. 1995;12:799-806. 
23. Duddu SP, Dal Monte PR. Effect of glass transition temperature on the stability of lyophilized formulations containing a chimeric therapeutic monoclonal antibody. Pharm Res. 1997;14:591-5.

24. Hancock BC, Shamblin SL. Molecular mobility of amorphous pharmaceuticals determined using differential scanning calorimetry. Thermochim Acta. 2001;380:95-107.

25. Correia NT, Moura Ramos JJ, Descamps M, Collins G. Molecular mobility and fragility in indomethacin: a thermally stimulated depolarization current study. Pharm Res. 2001;18: $1767-74$.

26. Six K, Verreck G, Peeters J, Augustijns P, Kinget R, Van den Mooter G. Characterization of glassy itraconazole: a comparative study of its molecular mobility below $\mathrm{Tg}$ with that of structural analogues using MTDSC. Int J Pharm. 2001;213:163-73.

27. Aso Y, Yoshioka S, Kojima S. Explanation of the crystallization rate of amorphous nifedipine and phenobarbital from their molecular mobility as measured by $13 \mathrm{C}$ nuclear magnetic resonance relaxation time and the relaxation time obtained from the heating rate dependence of the glass transition temperature. J Pharm Sci. 2001;90:798-806.

28. Hancock BC, Parks M. What is the true solubility advantage for amorphous pharmaceuticals? Pharm Res. 2000;17:397-404.

29. Loftsson T, Brewster ME. Pharmaceutical applications of cyclodextrins: basic science and product development. J Pharm Pharmacol. 2010;62:1607-21.

30. Bergström CAS, Charman WN, Porter CJH. Computational prediction of formulation strategies for beyond-rule-of- 5 compounds. Adv Drug Deliv Rev. 2016;101:6-21.

31. Leeson PD, St-Gallay SA. The influence of the 'organizational factor' on compound quality in drug discovery. Nat Rev Drug Discov. 2011;10:749-65.

32. Leeson PD, Springthorpe B. The influence of drug-like concepts on decision-making in medicinal chemistry. Nat Rev Drug Discov. 2007;6:881-90.

33. Morphy R. The influence of target family and functional activity on the physicochemical properties of pre-clinical compounds. J Med Chem. 2006;49:2969-78.

34. Wang H, Chen J, Hollister K, Sowers LC, Forman BM. Endogenous bile acids are ligands for the nuclear receptor FXR/BAR. Mol Cell. 1999;3:543-53.

35. Fu X, Menke JG, Chen Y, Zhou G, MacNaul KL, Wright SD, Sparrow CP, Lund EG. 27-hydroxycholesterol is an endogenous ligand for liver X receptor in cholesterol-loaded cells. J Biol Chem. 2001;276:38378-87.

36. Bergström CAS, Wassvik CM, Johansson K, Hubatsch I. Poorly soluble marketed drugs display solvation limited solubility. J Med Chem. 2007;50:5858-62.

37. Wassvik CM, Holmén AG, Draheim R, Artursson P, Bergström CAS. Molecular characteristics for solid-state limited solubility. J Med Chem. 2008;51:3035-9.

38. Zakowiecki D, Cal K, Kaminski K, Adrjanowicz K, Swinder L, Kaminska E, Garbacz G. The improvement of the dissolution rate of ziprasidone free base from solid oral formulations. AAPS Pharm SciTech. 2015;16:922-33.

39. Jensen KT, Lobmann K, Rades T, Grohganz H. Improving coamorphous drug formulations by the addition of the highly water soluble amino Acid, proline. Pharmaceutics. 2014;6:416-35.

40. Wairkar S, Gaud R. Co-amorphous combination of nateglinidemetformin hydrochloride for dissolution enhancement. AAPS Pharm Sci Tech. 2016;17:673-81.

41. Onoue S, Kojo Y, Aoki Y, Kawabata Y, Yamauchi Y, Yamada S. Physicochemical and pharmacokinetic characterization of amorphous solid dispersion of tranilast with enhanced solubility in gastric fluid and improved oral bioavailability. Drug Metab Pharmacokinet. 2012;27:379-87.
42. Choi JS, Park JS. Design of PVP/VA S-630 based tadalafil solid dispersion to enhance the dissolution rate. Eur J Pharm Sci. 2017;97:269-76.

43. Wei Q Keck CM, Muller RH. Oral hesperidin-Amorphization and improved dissolution properties by controlled loading onto porous silica. Int J Pharm. 2017;518:253-63.

44. Tehler U, Fagerberg JH, Svensson R, Larhed M, Artursson P, Bergström CAS. Optimizing solubility and permeability of a biopharmaceutics classification system (BCS) class 4 antibiotic drug using lipophilic fragments disturbing the crystal lattice. J Med Chem. 2013;56:2690-4.

45. Iwata K, Karashima M, Ikeda Y. Cocrystallization enhanced TAK-441 aqueous solubility and suppressed high solvatomorphism. Cryst Growth Des. 2016;16:4599-606.

46. Duggirala NK, Perry ML, Almarsson O, Zaworotko MJ. Pharmaceutical cocrystals: along the path to improved medicines. Chem Commun. 2016;52:640-55.

47. Seo JH, Park JB, Choi W-K, Park S, Sung YJ, Oh E, Bae SK. Improved oral absorption of cilostazol via sulfonate salt formation with mesylate and besylate. Drug Des Dev Ther. 2015;9:3961-8.

48. Varia SA, Stella VJ. Phenytoin prodrugs v: in vivo evaluation of some water-soluble phenytoin prodrugs in dogs. J Pharm Sci. 1984;73:1080-7.

49. Kumar S, Jog R, Shen J, Zolnik B, Sadrieh N, Burgess DJ. In vitro and in vivo performance of different sized spray-dried crystalline itraconazole. J Pharm Sci. 2015;104:3018-28.

50. Junghanns JU, Muller RH. Nanocrystal technology, drug delivery and clinical applications. Int J Nanomedicine. 2008;3:295-309.

51. Jog R, Kumar S, Shen J, Jugade N, Tan DC, Gokhale R, Burgess DJ. Formulation design and evaluation of amorphous ABT-102 nanoparticles. Int J Pharm. 2016;498:153-69.

52. Dong B, Hadinoto K. Amorphous nanoparticle complex of perphenazine and dextran sulfate as a new solubility enhancement strategy of antipsychotic perphenazine. Drug Dev Ind Pharm. 2017;43:996-1002.

53. Maniruzzaman M, Nair A, Renault M, Nandi U, Scoutaris N, Farnish R, Bradley MS, Snowden MJ, Douroumis D. Continuous twin-screw granulation for enhancing the dissolution of poorly water soluble drug. Int J Pharm. 2015;496:52-62.

54. Waring MJ, Arrowsmith J, Leach AR, Leeson PD, Mandrell S, Owen RM, Pairaudeau G, Pennie WD, Pickett SD, Wang J, Wallace $\mathrm{O}$, Weir A. An analysis of the attrition of drug candidates from four major pharmaceutical companies. Nat Rev Drug Discov. 2015;14:475-86.

55. Alhalaweh A, Alzghoul A, Kaialy W, Mahlin D, Bergström CAS. Computational predictions of glass-forming ability and crystallization tendency of drug molecules. Mol Pharm. 2014;1 1:3123-32.

56. Baird JA, Van Eerdenbrugh B, Taylor LS. A classification system to assess the crystallization tendency of organic molecules from undercooled melts. J Pharm Sci. 2010;99:3787-806.

57. Van Eerdenbrugh B, BairdJA, Taylor LS. Crystallization tendency of active pharmaceutical ingredients following rapid solvent evaporation-classification and comparison with crystallization tendency from under cooled melts. J Pharm Sci. 2010;99:382638.

58. Kawakami K, Harada T, Yoshihashi Y, Yonemochi E, Terada K, Moriyama $\mathrm{H}$. Correlation between glass-forming ability and fragility of pharmaceutical compounds. J Phys Chem B. 2015;119: 4873-80.

59. Jog R, Gokhale R, Burgess DJ. Solid state drug-polymer miscibility studies using the model drug ABT-102. Int J Pharm. 2016;509: 285-95.

60. Alhalaweh A, Alzghoul A, Kaialy W, Mahlin D, Bergstrom CA. Computational predictions of glass-forming ability and crystallization tendency of drug molecules. Mol Pharm. 2014;11:3123-32. 
61. Wyttenbach N, Kirchmeyer W, Alsenz J, Kuentz M. Theoretical considerations of the prigogine-defay ratio with regard to the glass-forming ability of drugs from undercooled melts. Mol Pharm. 2016;13:241-50.

62. Nurzyńska K, Booth J, Roberts CJ, McCabe J, Dryden I, Fischer PM. Long-term amorphous drug stability predictions using easily calculated, predicted, and measured parameters. Mol Pharm. 2015;12:3389-98.

63. Alhalaweh A, Alzghoul A, Mahlin D, Bergström CAS. Physical stability of drugs after storage above and below the glass transition temperature: Relationship to glass-forming ability. Int J Pharm. 2015;495:312-7.

64. Mahlin D, Ponnambalam S, Heidarian Höckerfelt M, Bergström CAS. Toward in silico prediction of glass-forming ability from molecular structure alone: a screening tool in early drug development. Mol Pharm. 2011;8:498-506.

65. Mahlin D, Bergström CAS. Early drug development predictions of glass-forming ability and physical stability of drugs. EurJ Pharm Sci. 2013;49:323-32

66. Lipinski CA, Lombardo F, Dominy BW, Feeney PJ. In vitro models for selection of development candidatesexperimental and computational approaches to estimate solubility and permeability in drug discovery and development settings. Adv Drug Deliv Rev. 1997;23:3-25.

67. Veber DF, Johnson SR, Cheng H-Y, Smith BR, Ward KW, Kopple KD. Molecular properties that influence the oral bioavailability of drug candidates. J Med Chem. 2002;45:2615-23.

68. Lu JJ, Crimin K, Goodwin JT, Crivori P, Orrenius C, Xing L, Tandler PJ, Vidmar TJ, Amore BM, Wilson AGE, Stouten PFW, Burton PS. Influence of molecular flexibility and polar surface area metrics on oral bioavailability in the rat. J Med Chem. 2004;47:6104-7.

69. Jog R, Burgess DJ. Pharmaceutical amorphous nanoparticles. J Pharm Sci. 106:39-65.

70. I.P.E. Council. The IPEG excipient composition guide. International Pharmaceutical Excipients Council (IPEC). 2009.

71. Verma S, Rudraraju VS. Wetting kinetics: an alternative approach towards understanding the enhanced dissolution rate for amorphous solid dispersion of a poorly soluble drug. AAPS PharmSciTech. 2015;16:1079-90.

72. Nagy ZK, Balogh A, Demuth B, Pataki H, Vigh T, Szabo B, Molnar K, Schmidt BT, Horak P, Marosi G, Verreck G, Van Assche I, Brewster ME. High speed electrospinning for scaled-up production of amorphous solid dispersion of itraconazole. Int J Pharm. 2015;480:137-42.

73. Ewing AV, Clarke GS, Kazarian SG. Stability of indomethacin with relevance to the release from amorphous solid dispersions studied with ATR-FTIR spectroscopic imaging. Eur J Pharm Sci. 2014;60:64-71.

74. Balogh A, Dravavolgyi G, Farago K, Farkas A, Vigh T, Soti PL, Wagner I, Madarasz J, Pataki H, Marosi G, Nagy ZK. Plasticized drug-loaded melt electrospun polymer mats: characterization, thermal degradation, and release kinetics. J Pharm Sci. 2014;103:1278-87.

75. Mosquera-Giraldo LI, Trasi NS, Taylor LS. Impact of surfactants on the crystal growth of amorphous celecoxib. Int J Pharm. 2014;461:251-7.

76. Tian Y, Caron V, Jones DS, Healy AM, Andrews GP. Using Flory-Huggins phase diagrams as a pre-formulation tool for the production of amorphous solid dispersions: a comparison between hot-melt extrusion and spray drying. J Pharm Pharmacol. 2014:66:256-74.

77. Lee TW, Boersen NA, Yang G, Hui HW. Evaluation of different screening methods to understand the dissolution behaviors of amorphous solid dispersions. Drug Dev Ind Pharm. 2014;40: 1072-83.
78. Yadav PS, Kumar V, Singh UP, Bhat HR, Mazumder B. Physicochemical characterization and in vitro dissolution studies of solid dispersions of ketoprofen with PVP K30 and d-mannitol. Saudi Pharm J. 2013;21:77-84.

79. Priemel PA, Laitinen R, Grohganz H, Rades T, Strachan CJ. In situ amorphisation of indomethacin with Eudragit $(\mathrm{R}) \mathrm{E}$ during dissolution. Eur J Pharm Biopharm. 2013;85:1259-65.

80. Ilevbare GA, Liu H, Pereira J, Edgar KJ, Taylor LS. Influence of additives on the properties of nanodroplets formed in highly supersaturated aqueous solutions of ritonavir. Mol Pharm. 2013;10: 3392-403.

81. Sotthivirat S, McKelvey C, Moser J, Rege B, Xu W, Zhang D. Development of amorphous solid dispersion formulations of a poorly water-soluble drug, MK-0364. Int J Pharm. 2013;452: 73-81.

82. Hu Q Choi DS, Chokshi H, Shah N, Sandhu H. Highly efficient miniaturized coprecipitation screening (MiCoS) for amorphous solid dispersion formulation development. Int J Pharm. 2013;450:53-62.

83. Tran TH, Poudel BK, Marasini N, Chi SC, Choi HG, Yong CS, Kim JO. Preparation and evaluation of raloxifene-loaded solid dispersion nanoparticle by spray-drying technique without an organic solvent. Int J Pharm. 2013;443:50-7.

84. ParkJ, Cho W, Cha KH, Ahn J, Han K, Hwang SJ. Solubilization of the poorly water soluble drug, telmisartan, using supercritical anti-solvent (SAS) process. Int J Pharm. 2013;441:50-5.

85. Marasini N, Tran TH, Poudel BK, Cho HJ, Choi YK, Chi SC, Choi HG, Yong CS, Kim JO. Fabrication and evaluation of pHmodulated solid dispersion for telmisartan by spray-drying technique. Int J Pharm. 2013;441:424-32.

86. Kolasinac N, Kachrimanis K, Djuris J, Homsek I, Grujic B, Ibric S. Spray coating as a powerful technique in preparation of solid dispersions with enhanced desloratadine dissolution rate. Drug Dev Ind Pharm. 2013;39:1020-7.

87. Park CW, Tung NT, Rhee YS, Kim JY, Oh TO, Ha JM, Chi SC, Park ES. Physicochemical, pharmacokinetic and pharmacodynamic evaluations of novel ternary solid dispersion of rebamipide with poloxamer 407. Drug Dev Ind Pharm. 2013;39:836-44.

88. Nishino Y, Kubota A, Kanazawa T, Takashima Y, Ozeki T, Okada H. Improved intestinal absorption of a poorly watersoluble oral drug using mannitol microparticles containing a nanosolid drug dispersion. J Pharm Sci. 2012;101:4191-200.

89. Xiangand T-X, Anderson BD. Molecular dynamics simulation of amorphous indomethacin-poly(vinylpyrrolidone) glasses: solubility and hydrogen bonding interactions. J Pharm Sci. 2013;102:87691.

90. Dinunzio JC, Schilling SU, Coney AW, Hughey JR, Kaneko N, McGinity JW. Use of highly compressible Ceolus microcrystalline cellulose for improved dosage form properties containing a hydrophilic solid dispersion. Drug Dev Ind Pharm. 2012;38:180-9.

91. Yu DG, Zhu LM, Branford-White CJ, Yang JH, Wang X, Li Y, Qian W. Solid dispersions in the form of electrospun core-sheath nanofibers. Int J Nanomedicine. 201 1;6:3271-80.

92. Kim MS, Kim JS, Park HJ, Cho WK, Cha KH, Hwang SJ. Enhanced bioavailability of sirolimus via preparation of solid dispersion nanoparticles using a supercritical antisolvent process. Int J Nanomedicine. 201 1;6:2997-3009.

93. Rumondor AC, Wikstrom H, Van Eerdenbrugh B, Taylor LS. Understanding the tendency of amorphous solid dispersions to undergo amorphous-amorphous phase separation in the presence of absorbed moisture. AAPS PharmSciTech. 2011;12:1209-19.

94. Huang J, Li Y, Wigent RJ, Malick WA, Sandhu HK, Singhal D, Shah NH. Interplay of formulation and process methodology on the extent of nifedipine molecular dispersion in polymers. Int J Pharm. 201 1;420:59-67. 
95. Kakran M, Sahoo NG, Li L. Dissolution enhancement of quercetin through nanofabrication, complexation, and solid dispersion. Colloids Surf B: Biointerfaces. 201 1;88:121-30.

96. Weuts I, Van Dycke F, Voorspoels J, De Cort S, Stokbroekx S, Leemans R, Brewster ME, Xu D, Segmuller B, Turner YT, Roberts CJ, Davies MC, Qi S, Craig DQ, Reading M. Physicochemical properties of the amorphous drug, cast films, and spray dried powders to predict formulation probability of success for solid dispersions: etravirine. J Pharm Sci. 2011;100: 260-74.

97. Knopp MM, Chourak N, Khan F, Wendelboe J, Langguth P, Rades T, Holm R. Effect of polymer type and drug dose on the in vitro and in vivo behavior of amorphous solid dispersions. Eur J Pharm Biopharm. 2016;105:106-14.

98. Puncochova K, Vukosavljevic B, Hanus J, Beranek J, Windbergs M, Stepanek F. Non-invasive insight into the release mechanisms of a poorly soluble drug from amorphous solid dispersions by confocal Raman microscopy. Eur J Pharm Biopharm. 2016;101: 119-25.

99. Tres F, Treacher K, Booth J, Hughes LP, Wren SA, Aylott JW, Burley JC. Indomethacin-Kollidon VA64 extrudates: a mechanistic study of ph-dependent controlled release. Mol Pharm. 2016;13:1166-75.

100. Sun DD, Lee PI. Evolution of supersaturation of amorphous pharmaceuticals: nonlinear rate of supersaturation generation regulated by matrix diffusion. Mol Pharm. 2015;12:1203-15.

101. Puncochova K, Ewing AV, Gajdosova M, Sarvasova N, Kazarian SG, Beranek J, Stepanek F. Identifying the mechanisms of drug release from amorphous solid dispersions using MRI and ATRFTIR spectroscopic imaging. Int J Pharm. 2015;483:256-67.

102. Tabbakhian M, Hasanzadeh F, Tavakoli N, Jamshidian Z. Dissolution enhancement of glibenclamide by solid dispersion: solvent evaporation versus a supercritical fluid-based solvent antisolvent technique. Res Pharm Sci. 2014;9:337-50.

103. Ramadhani N, Shabir M, McConville C. Preparation and characterisation of Kolliphor(R) P 188 and P 237 solid dispersion oral tablets containing the poorly water soluble drug disulfiram. Int J Pharm. 2014:475:514-22.

104. Prasad D, Chauhan H, Atef E. Amorphous stabilization and dissolution enhancement of amorphous ternary solid dispersions: combination of polymers showing drug-polymer interaction for synergistic effects. J Pharm Sci. 2014;103:3511-23.

105. Sarode AL, Malekar SA, Cote C, Worthen DR. Hydroxypropyl cellulose stabilizes amorphous solid dispersions of the poorly water soluble drug felodipine. Carbohydr Polym. 2014;112:512-9.

106. Tres F, Treacher K, Booth J, Hughes LP, Wren SA, Aylott JW, Burley JC. Real time Raman imaging to understand dissolution performance of amorphous solid dispersions. J Control Release. 2014;188:53-60.

107. Kumar S, Linehan B, Tseng YC. A new combination approach of CI jet and QESD to formulate pH-susceptible amorphous solid dispersions. Int J Pharm. 2014;466:368-74.

108. Higashi K, Yamamoto K, Pandey MK, Mroue KH, Moribe K, Yamamoto K, Ramamoorthy A. Insights into atomic-level interaction between mefenamic acid and eudragit EPO in a supersaturated solution by high-resolution magic-angle spinning NMR spectroscopy. Mol Pharm. 2014;11:351-7.

109. Xu M, Zhang C, Luo Y, Xu L, Tao X, Wang Y, He H, Tang X. Application and functional characterization of POVACOAT, a hydrophilic co-polymer poly(vinyl alcohol/acrylic acid/methyl methacrylate) as a hot-melt extrusion carrier. Drug Dev Ind Pharm. 2014;40:126-35.

110. Patel VI, Dave RH. Evaluation of colloidal solid dispersions: physiochemical considerations and in vitro release profile. AAPS PharmSciTech. 2013;14:620-8.
111. Khan S, Batchelor H, Hanson P, Saleem IY, Perrie Y, Mohammed AR. Dissolution rate enhancement, in vitro evaluation and investigation of drug release kinetics of chloramphenicol and sulphamethoxazole solid dispersions. Drug Dev Ind Pharm. 2013;39:704-15.

112. Kushida I, Gotoda M. Investigation for the amorphous state of ER-34122, a dual 5-lipoxygenase/cyclooxygenase inhibitor with poor aqueous solubility, in HPMC solid dispersion prepared by the solvent evaporation method. Drug Dev Ind Pharm. 2013;39: 1582-8.

113. Reven S, Homar M, Peternel L, Kristl J, Zagar E. Preparation and characterization of tablet formulation based on solid dispersion of glimepiride and poly(ester amide) hyperbranched polymer. Pharm Dev Technol. 2013;18:323-32.

114. Kolasinac N, Kachrimanis K, Homsek I, Grujic B, Ethuric Z, Ibric S. Solubility enhancement of desloratadine by solid dispersion in poloxamers. Int J Pharm. 2012;436:161-70.

115. Chiang PC, Ran Y, Chou KJ, Cui Y, Sambrone A, Chan C, Hart R. Evaluation of drug load and polymer by using a 96-well plate vacuum dry system for amorphous solid dispersion drug delivery. AAPS PharmSciTech. 2012;13:713-22.

116. Jondhale S, Bhise S, Pore Y. Physicochemical investigations and stability studies of amorphous gliclazide. AAPS PharmSciTech. 2012;13:448-59.

117. Wan S, Sun Y, Qi X, Tan F. Improved bioavailability of poorly water-soluble drug curcumin in cellulose acetate solid dispersion. AAPS PharmSciTech. 2012;13:159-66.

118. Chen Y, Shi Q, Chen Z, ZhengJ, Xu H, LiJ, Liu H. Preparation and characterization of emulsified solid dispersions containing docetaxel. Arch Pharm Res. 201 1;34:1909-17.

119. Ghosh I, Snyder J, Vippagunta R, Alvine M, Vakil R, Tong WQ, Vippagunta S. Comparison of HPMC based polymers performance as carriers for manufacture of solid dispersions using the melt extruder. Int J Pharm. 2011;419:12-9.

120. Capece M, Davé R. Enhanced physical stability of amorphous drug formulations via dry polymer coating. J Pharm Sci. 2015;104:2076-84.

121. Lang B, Liu S, McGinity JW, Williams RO. Effect of hydrophilic additives on the dissolution and pharmacokinetic properties of itraconazole-enteric polymer hot-melt extruded amorphous solid dispersions. Drug Dev Ind Pharm. 2016;42:429-45.

122. Gu B, Linehan B, Tseng Y-C. Optimization of the Büchi B-90 spray drying process using central composite design for preparation of solid dispersions. Int J Pharm. 2015;491:208-17.

123. Senta-Loys Z, Bourgeois S, Valour JP, Briancon S, Fessi H. Orodispersible films based on amorphous solid dispersions of tetrabenazine. Int J Pharm. 2017;518:242-52.

124. Al-Obaidi H, Lawrence MJ, Buckton G. Atypical effects of incorporated surfactants on stability and dissolution properties of amorphous polymeric dispersions. J Pharm Pharmacol. 2016;68:137383.

125. Liand N, Taylor LS. Nanoscale infrared, thermal, and mechanical characterization of telaprevir-polymer miscibility in amorphous solid dispersions prepared by solvent evaporation. Mol Pharm. 2016;13:1123-36.

126. Meng F, Trivino A, Prasad D, Chauhan H. Investigation and correlation of drug polymer miscibility and molecular interactions by various approaches for the preparation of amorphous solid dispersions. Eur J Pharm Sci. 2015;7 1:12-24.

127. Alshahrani SM, Lu W, Park JB, Morott JT, Alsulays BB, Majumdar S, Langley N, Kolter K, Gryczke A, Repka MA. Stability-enhanced hot-melt extruded amorphous solid dispersions via combinations of Soluplus $(\mathrm{R})$ and HPMCAS-HF. AAPS PharmSciTech. 2015;16:824-34.

128. Sarode AL, Wang P, Obara S, Worthen DR. Supersaturation, nucleation, and crystal growth during single- and biphasic 
dissolution of amorphous solid dispersions: polymer effects and implications for oral bioavailability enhancement of poorly water soluble drugs. Eur J Pharm Biopharm. 2014;86:351-60.

129. Yang Z, Nollenberger K, Albers J, Craig D, Qi S. Microstructure of an immiscible polymer blend and its stabilization effect on amorphous solid dispersions. Mol Pharm. 2013;10:2767-80.

130. Tran PH, Tran TT, Piao ZZ, Vo TV, Park JB, Lim J, Oh KT, Rhee YS, Lee BJ. Physical properties and in vivo bioavailability in human volunteers of isradipine using controlled release matrix tablet containing self-emulsifying solid dispersion. Int J Pharm. 2013;450:79-86.

131. Al-Obaidi H, Lawrence MJ, Shah S, Moghul H, Al-Saden N, Bari F. Effect of drug-polymer interactions on the aqueous solubility of milled solid dispersions. Int J Pharm. 2013;446:100-5.

132. Leane MM, Sinclair W, Qian F, Haddadin R, Brown A, Tobyn $\mathrm{M}$, Dennis AB. Formulation and process design for a solid dosage form containing a spray-dried amorphous dispersion of ibipinabant. Pharm Dev Technol. 2013;18:359-66.

133. Duret C, Wauthoz N, Sebti T, Vanderbist F, Amighi K. Solid dispersions of itraconazole for inhalation with enhanced dissolution, solubility and dispersion properties. Int J Pharm. 2012;428: $103-13$

134. Al-Obaidi H, Ke P, Brocchini S, Buckton G. Characterization and stability of ternary solid dispersions with PVP and PHPMA. Int J Pharm. 2011;419:20-7.

135. Kanaujia P, Lau G, Ng WK, Widjaja E, Hanefeld A, Fischbach M, Maio M, Tan RB. Nanoparticle formation and growth during in vitro dissolution of ketoconazole solid dispersion. J Pharm Sci. 201 1;100:2876-85.

136. Jung HJ, Ahn HI, Park JY, Ho MJ, Lee DR, Cho HR, Park JS, Choi YS, Kang MJ. Improved oral absorption of tacrolimus by a solid dispersion with hypromellose and sodium lauryl sulfate. Int J Biol Macromol. 2016;83:282-7.

137. Wlodarski K, Sawicki W, Haber K, Knapik J, Wojnarowska Z, Paluch M, Lepek P, Hawelek L, Tajber L. Physicochemical properties of tadalafil solid dispersions - Impact of polymer on the apparent solubility and dissolution rate of tadalafil. Eur J Pharm Biopharm. 2015;94:106-15.

138. Bennett RC, Keen JM, Bi Y, Porter S, Dürig T, McGinity JW. Investigation of the interactions of enteric and hydrophilic polymers to enhance dissolution of griseofulvin following hot melt extrusion processing. J Pharm Pharmacol. 2015;67:918-38.

139. Liu J, Zou M, Piao H, Liu Y, Tang B, Gao Y, Ma N, Cheng G. Characterization and pharmacokinetic study of aprepitant solid dispersions with soluplus ${ }^{\circledR}$. Molecules. 2015;20:11,345.

140. Xiangand TX, Anderson BD. Molecular dynamics simulation of amorphous hydroxypropylmethylcellulose and its mixtures with felodipine and water. J Pharm Sci. 2017;106:803-16.

141. Borbas E, Sinko B, Tsinman O, Tsinman K, Kiserdei E, Demuth B, Balogh A, Bodak B, Domokos A, Dargo G, Balogh GT, Nagy ZK. Investigation and mathematical description of the real driving force of passive transport of drug molecules from supersaturated solutions. Mol Pharm. 2016;13:3816-26.

142. Puncochova K, Ewing AV, Gajdosova M, Pekarek T, Beranek J, Kazarian SG, Stepanek F. The combined use of imaging approaches to assess drug release from multicomponent solid dispersions. Pharm Res. 2016;34:990-1001.

143. Brough G, Miller DA, Ellenberger D, Lubda D, Williams RO 3rd. Use of polyvinyl alcohol as a solubility enhancing polymer for poorly water-soluble drug delivery (part 2). AAPS PharmSciTech. 2016;17:180-90.

144. Xie T, Taylor LS. Improved release of celecoxib from high drug loading amorphous solid dispersions formulated with polyacrylic acid and cellulose derivatives. Mol Pharm. 2016;13:873-84.

145. Knopp MM, Nguyen JH, Mu H, Langguth P, Rades T, Holm R. Influence of copolymer composition on in vitro and in vivo performance of celecoxib-PVP/VA amorphous solid dispersions. AAPS J. 2016;18:416-23.

146. Martinez-Marcos L, Lamprou DA, McBurney RT, Halbert GW. A novel hot-melt extrusion formulation of albendazole for increasing dissolution properties. Int J Pharm. 2016;499:175-85.

147. Brough C, Miller DA, Keen JM, Kucera SA, Lubda D, Williams RO 3rd. Use of polyvinyl alcohol as a solubility-enhancing polymer for poorly water soluble drug delivery (part 1). AAPS PharmSciTech. 2016;17:167-79.

148. Pandey MM, Jaipal A, Charde SY, Goel P, Kumar L. Dissolution enhancement of felodipine by amorphous nanodispersions using an amphiphilic polymer: insight into the role of drug-polymer interactions on drug dissolution. Pharm Dev Technol. 2016;21: 463-74.

149. Potter C, Tian Y, Walker G, McCoy C, Hornsby P, Donnelly C, Jones DS, Andrews GP. Novel supercritical carbon dioxide impregnation technique for the production of amorphous solid drug dispersions: a comparison to hot melt extrusion. Mol Pharm. 2015; 12:1377-90.

150. Huang S, O'Donnell KP, Keen JM, Rickard MA, McGinity JW Williams RO. A new extrudable form of hypromellose: AFFINISOL ${ }^{\text {TM }}$ HPMC HME. AAPS PharmSciTech. 2016;17: 106-19.

151. LaFountaine JS, Jermain SV, Prasad LK, Brough C, Miller DA, Lubda D, McGinity JW, Williams RO 3rd. Enabling thermal processing of ritonavir-polyvinyl alcohol amorphous solid dispersions by KinetiSol(R) Dispersing. Eur J Pharm Biopharm. 2016;101:72-81.

152. Thiry J, Broze G, Pestieau A, Tatton AS, Baumans F, Damblon C, Krier F, Evrard B. Investigation of a suitable in vitro dissolution test for itraconazole-based solid dispersions. Eur J Pharm Sci. 2016;85:94-105.

153. Paaver U, Heinamaki J, Laidmae I, Lust A, Kozlova J, Sillaste E, Kirsimae K, Veski P, Kogermann K. Electrospun nanofibers as a potential controlled-release solid dispersion system for poorly water-soluble drugs. Int J Pharm. 2015;479:252-60.

154. Tran HT, Park JB, Hong KH, Choi HG, Han HK, Lee J, Oh KT, Lee BJ. Preparation and characterization of $\mathrm{pH}$-independent sustained release tablet containing solid dispersion granules of a poorly water-soluble drug. Int J Pharm. 2011;415:83-8.

155. Adler C, Schönenberger M, Teleki A, Kuentz M. Molecularly designed lipid microdomains for solid dispersions using a polymer/inorganic carrier matrix produced by hot-melt extrusion. Int J Pharm. 2016;499:90-100.

156. Shergill M, Patel M, Khan S, Bashir A, McGonville C. Development and characterisation of sustained release solid dispersion oral tablets containing the poorly water soluble drug disulfiram. Int J Pharm. 2016;497:3-1 1.

157. Ting JM, Tale S, Purchel AA, Jones SD, Widanapathirana L, Tolstyka ZP, Guo L, Guillaudeu SJ, Bates FS, Reineke TM. High-throughput excipient discovery enables oral delivery of poorly soluble pharmaceuticals. ACS Cent Sci. 2016;2:748-55.

158. Urbanova M, Sturcova A, Kredatusova J, Brus J. Structural insight into the physical stability of amorphous Simvastatin dispersed in pHPMA: enhanced dynamics and local clustering as evidenced by solid-state NMR and Raman spectroscopy. Int J Pharm. 2015;478:464-75.

159. Yang M, Wang P, Gogos C. Prediction of acetaminophen's solubility in poly(ethylene oxide) at room temperature using the FloryHuggins theory. Drug Dev Ind Pharm. 2013;39:102-8.

160. Widanapathirana L, Tale S, Reineke TM. Dissolution and solubility enhancement of the highly lipophilic drug phenytoin via interaction with poly(N-isopropylacrylamide-co-vinylpyrrolidone) excipients. Mol Pharm. 2015;12:2537-43.

161. Raimi-Abraham BT, Mahalingam S, Davies PJ, Edirisinghe M, Craig DQM. Development and characterization of amorphous 
nanofiber drug dispersions prepared using pressurized gyration. Mol Pharm. 2015;12:3851-61.

162. Yuan X, Sperger D, Munson EJ. Investigating miscibility and molecular mobility of nifedipine-PVP amorphous solid dispersions using solid-state NMR spectroscopy. Mol Pharm. 2014;11:32937.

163. Huang Y, Dai W-G. Fundamental aspects of solid dispersion technology for poorly soluble drugs. Acta Pharm Sin B. 2014;4:18-25.

164. Wyttenbach N, Kuentz M. Glass-forming ability of compounds in marketed amorphous drug products. Eur J Pharm Biopharm. 2017;112:204-8.

165. Siew A. Solving poor solubility with amorphous solid dispersions. Weighing the pros and cons of hot-melt extrusion and spray drying, Vol. 38. 2014. PharmTech.com.

166. Bennett RC, Brough C, Miller DA, O'Donnell KP, Keen JM, Hughey JR, Williams RO, McGinity JW. Preparation of amorphous solid dispersions by rotary evaporation and KinetiSol dispersing: approaches to enhance solubility of a poorly water-soluble gum extract. Drug Dev Ind Pharm. 2015;41:382-97.

167. Janssens S, Anné M, Rombaut P, Van den Mooter G. Spray drying from complex solvent systems broadens the applicability of Kollicoat IR as a carrier in the formulation of solid dispersions. Eur J Pharm Sci. 2009;37:241-8.

168. Jackson MJ, Kestur US, Hussain MA, Taylor LS. Dissolution of danazol amorphous solid dispersions: supersaturation and phase behavior as a function of drug loading and polymer type. Mol Pharm. 2016;13:223-31.

169. Lust A, Strachan CJ, Veski P, Aaltonen J, HeinämäkiJ, Yliruusi J, Kogermann K. Amorphous solid dispersions of piroxicam and Soluplus ${ }^{\circledR}:$ Qualitative and quantitative analysis of piroxicam recrystallization during storage. Int J Pharm. 2015;486:306-14.

170. Xu W-J, Xie H-J, Cao Q-R, Shi L-L, Cao Y, Zhu X-Y, Cui J-H. Enhanced dissolution and oral bioavailability of valsartan solid dispersions prepared by a freeze-drying technique using hydrophilic polymers. Drug Deliv. 2016;23:41-8.

171. Kang N, Lee J, Choi JN, Mao C, Lee EH. Cryomilling-induced solid dispersion of poor glass forming/poorly water-soluble mefenamic acid with polyvinylpyrrolidone K12. Drug Dev Ind Pharm. 2015;41:978-88.

172. Penkina A, Semjonov K, Hakola M, Vuorinen S, Repo T, Yliruusi J, Aruväli J, Kogermann K, Veski P, Heinämäki J. Towards improved solubility of poorly water-soluble drugs: cryogenic co-grinding of piroxicam with carrier polymers. Drug Dev Ind Pharm. 2016;42:378-88.

173. Trasi NS, Taylor LS. Dissolution performance of binary amorphous drug combinations - Impact of a second drug on the maximum achievable supersaturation. Int J Pharm. 2015;496:282-90.

174. Liu ZP, Cui L, Yu DG, Zhao ZX, Chen L. Electrosprayed coreshell solid dispersions of acyclovir fabricated using an epoxycoated concentric spray head. Int J Nanomedicine. 2014;9: 1967-77.

175. Zecevic DE, Meier R, Daniels R, Wagner KG. Site specific solubility improvement using solid dispersions of HPMC-AS/HPC SSL-mixtures. EurJ Pharm Biopharm. 2014;87:264-70.

176. Salmani JM, Lv H, Asghar S, Zhou J. Amorphous solid dispersion with increased gastric solubility in tandem with oral disintegrating tablets: a successful approach to improve the bioavailability of atorvastatin. Pharm Dev Technol. 2015;20:465-72.

177. Edueng K, Mahlin D, Larsson P, Bergstrom CAS. Mechanismbased selection of stabilization strategy for amorphous formulations: Insights into crystallization pathways. J Control Release. 2017; doi:10.1016/j.jconrel.2017.04.015.

178. Alzghoul A, Alhalaweh A, Mahlin D, Bergström CAS Experimental and computational prediction of glass transition temperature of drugs. J Chem Inf Model. 2014;54:3396-403.

179. Blaabjerg LI, Lindenberg E, Löbmann K, Grohganz H, Rades T. Glass forming ability of amorphous drugs investigated by continuous cooling and isothermal transformation. Mol Pharm. 2016;13:3318-25.

180. Six K, Murphy J, Weuts I, Craig DQM, Verreck G, Peeters J, Brewster M, Van den Mooter G. Identification of phase separation in solid dispersions of itraconazole and Eudragit ${ }^{\circledR}$ E100 using microthermal analysis. Pharm Res. 2003;20:135-8.

181. Paudel A, Geppi M, Van den Mooter G. Structural and dynamic properties of amorphous solid dispersions: the role of solid-state nuclear magnetic resonance spectroscopy and relaxometry. J Pharm Sci. 2014;103:2635-62.

182. Alonzo DE, Gao Y, Zhou D, Mo H, Zhang GG, Taylor LS. Dissolution and precipitation behavior of amorphous solid dispersions. J Pharm Sci. 2011;100:3316-31.

183. Xiang T-X, Anderson BD. Molecular dynamics simulation of amorphous indomethacin. Mol Pharm. 2013;10:102-14.

184. Xiang T-X, Anderson BD. Molecular dynamics simulation of amorphous hydroxypropyl-methylcellulose acetate succinate (HPMCAS): polymer model development, water distribution, and plasticization. Mol Pharm. 2014;11:2400-11.

185. Xiang TX, Anderson BD. Water uptake, distribution, and mobility in amorphous poly(d,l-lactide) by molecular dynamics simulation. J Pharm Sci. 2014;103:2759-71.

186. Fule R, Amin P. Hot melt extruded amorphous solid dispersion of posaconazole with improved bioavailability: investigating drugpolymer miscibility with advanced characterisation. Biomed Res Int. 2014;2014:146,781.

187. Ye X, Li Z-W, Sun Z-Y, Khomami B. Template-free bottom-up method for fabricating diblock copolymer patchy particles. ACS Nano. 2016;10:5199-203.

188. Schreck JS, Romano F, Zimmer MH, Louis AA, Doye JPK. Characterizing DNA star-tile-based nanostructures using a coarse-grained model. ACS Nano. 2016;10:4236-47.

189. Sun M, Li B, Li Y, Liu Y, Liu Q Jiang H, He Z, Zhao Y, Sun J. Experimental observations and dissipative particle dynamic simulations on microstructures of ph-sensitive polymer containing amorphous solid dispersions. Int J Pharm. 2016;517:185-95.

190. Anwar J, Khan S, Lindfors L. Secondary crystal nucleation: nuclei breeding factory uncovered. Angew Chem Int Ed. 2015;54:14, 681-4.

191. Kataoka M, Masaoka Y, Yamazaki Y, Sakane T, Sezaki H, Yamashita S. In vitro system to evaluate oral absorption of poorly water-soluble drugs: simultaneous analysis on dissolution and permeation of drugs. Pharm Res. 2003;20:1674-80. 